\title{
Small-Business Survival Capabilities and Fiscal Programs: Evidence from Oakland
}

\author{
Robert P. Bartlett III \\ University of California, Berkeley \\ rbartlett@berkeley.edu \\ Adair Morse \\ U.S. Department of the Treasury and University of California, Berkeley \\ adair@berkeley.edu (corresponding author)
}

\begin{abstract}
Using City of Oakland data during COVID-19, we document that small-business components of survival capabilities (i.e., revenue resiliency, labor flexibility, and committed costs) vary by firm size. Nonemployer businesses rely on low-cost structures to survive. Microbusinesses (1-5 employees) depend on 14\% greater revenue resiliency. Enterprises (6-50 employees) use labor flexibility to survive but face $10 \%-20 \%$ higher residual closure risk from committed costs. The evidence argues for size targeting of financial support programs, including committed costs and revenue-based lending programs. Supporting the capabilities mapping, we find that the Paycheck Protection Program (PPP) increased medium-run survival probability by $20.5 \%$ specifically for microbusinesses.
\end{abstract}

\section{Introduction}

In the United States, small businesses encompass 25.7 million nonemployer firms, 5.8 million microbusinesses (1-5 employees), and 2.8 million larger small-business enterprises (6-100 workers), together accounting for $44 \%$ of

The views and analyses in this article are those of the authors and do not represent the policies or agenda of the U.S. Department of the Treasury. We extend our thanks to the staff of the City of Oakland, whose foresight in implementing the survey used in this article and countless hours of work on it are a testament to the desire to support the people and small businesses of Oakland. Particular thanks go to Marisa Raya. We also thank the SafeGraph and HomeBase companies, which generously shared their data for research related to COVID-19's impact on U.S. businesses. For helpful comments and suggestions, we thank Raj Chetty, Ran Duchin, Michael Faulkender, Jarrad Harford, Peter Molk, Danny Sokol, Philip Strahan, Annette VissingJørgensen, and Andrew Winden, as well as seminar participants at the University of California, Berkeley; the University of Florida School of Law; the University of Illinois; the Ohio State University; the University of St. Gallen; the Swiss Finance Institute; the Bank of Mexico; Cornell University; the New York Federal Reserve Bank; the University of Frankfurt; Vanderbilt Law School; and participants at the 2021 Allied Social Sciences Association (ASSA) Annual Meeting, the Columbia School of International and Public Affairs (SIPA)/Bank Policy Institute (BPI) February 2021 Conference on Bank Regulation, the NBER Fall 2020 Entrepreneurship Working Group, the 2021 Journal of Financial and Quantitative Analysis (JFQA) Symposium on COVID-19, and the 2021 Societies for Financial Studies (SFS) Cavalcade North America. 
U.S. employment and 99\% of firms (2015 and 2017 U.S. Census data, https:// www.census.gov/programs-surveys/susb/technical-documentation/methodology.html). These 34 million businesses are heterogeneous in their toolkits to adapt to business-cycle fluctuations in a very simple way, by firm size. Such heterogeneity implies that a one-size-fits-all policy approach in a time of crisis is likely suboptimal.

In this article, we analyze the role of the ex ante employment size of a small business in survival, working through mechanisms of revenue resiliency, labor flexibility, and committed costs. These results build on the emerging literature examining the economic consequences of the COVID-19 pandemic on the smallbusiness sector. For example, Bartik, Bertrand, Cullen, Glaeser, Luca, and Stanton (BBCGLS) (2020), Humphries, Neilson, and Ulyssea (2020), Fairlie (2020), Alekseev, Amer, Gopal, Kuchler, Schneider, Stroebel, and Wernerfelt (2020), Kim, Parker, and Schoar (2020), and Adams, Boneva, Golin, and Rauh (2020) document many of the patterns of distress within the sector during the pandemic, including the high incidence of both temporary closures and mass layoffs, speaking to subjects we also study in the setting of Oakland, California. Our evidence, however, changes the perspective to survival mechanisms and adds to this body of work by analyzing the capabilities of survival by firm size.

We then examine the compatibility of these different survival capabilities with alternative small-business fiscal support programs, such as working capital loans, labor-cost subsidies, and lease/debt payment-restructuring programs. Our final analysis tests for the effectiveness of the Paycheck Protection Program (PPP) and Pandemic Unemployment Assistance (PUA) for small businesses and business owners with respect to short- and medium-run survival. In this regard, we build on the PPP employment outcome evidence in BBCGLS (2020), Chetty, Friedman, Hendren, Stepner, and the Opportunity Insights Team (2020), and Granja, Makridis, Yannelis, and Zwick (2020); the PPP short-term firm-survival analysis in Bartik, Cullen, Glaeser, Luca, Stanton, and Sunderam (BCGLSS) (2020) and Granja et al. (2020); and the PUA household-outcome evidence in Bhutta, Blair, Dettling, and Moo (2020) and Iverson, Kluender, Wang, and Yang (2020).

Our empirical contributions are cast in a novel framework whereby small businesses facing an adverse macro shock face survival as a function of their endowment of i) revenue resiliency, ii) labor-cost flexibility, and iii) committed costs (e.g., lease and loan payments). We illustrate here the importance of these dimensions in our main findings using a stylized, previewing example involving three restaurants. The first is a nonemployer caterer where the owner does everything. The second is a taqueria with a total employee base of 4 people, each able to handle all core functions. The third is a growing pizza restaurant employing 5 cooks and 20 waitstaff.

In this stylized illustration, the macro shock causes large revenue reductions for the high-volume pizza restaurant, but the owner can easily scale back employees because only a few employees (the cooks) provide the core function of pizza production. ${ }^{1}$ This labor flexibility does not put the owner at ease, however, because large

\footnotetext{
${ }^{1}$ U.S. workers are typically "at-will" employees and can be terminated at any time, regardless of employee performance. Nor do federal or state laws requiring advance notice of layoffs apply to businesses having only a few dozen or fewer employees. For instance, the federal Worker Adjustment and Retraining Notification (WARN) Act requires all U.S. employers to provide at least 60 days' advance notice before a
} 
committed costs (e.g., a large commercial lease and capital loans) loom. For instance, BCGLSS (2020) find that among survey respondents, the median business had expenses of over $\$ 10,000$ per month but only enough cash on hand to last for 2 weeks.

At the other end of firm size stands the caterer, who bears no labor cost other than her own sustenance. Like most nonemployers, the caterer has little growth expectations and low operating margins, implying that she has low committed costs. She also relies only on herself, which makes revenue pivots potentially challenging. Often, whether or not the caterer can withstand the shock depends on her personal savings and personal utility. ${ }^{2}$

The taqueria, unlike the pizza restaurant, has very constrained labor flexibility because the decision to lay off a cook (at the core of the production) would be tantamount to closing. On committed costs, the taqueria owner is likely to be similar to the nonemployer in having kept committed costs low because its small (but vital) labor force implies that it, too, has low growth expectations. Yet the strain of paying employees forces the taqueria to look for ways to maintain sufficient revenue to continue in operation, a tough setting that requires innovation aided only by having more than one core employee to assist in this endeavor. In the context of the COVID-19 pandemic, this decision to pursue revenue resiliency has been captured within the media as the small-business "pivot" ("For Small Businesses, It's All About the Pivot," New York Times, June 26, 2020), such as transitioning to pick-up only, providing remote services, moving to outdoor venues, and similar efforts to adjust business operations as a result of the public health crisis.

Our empirical contributions emerge out of analyses across 4 data sets. First are 2 unique survey data sets obtained from approximately 1,000 small businesses located in Oakland, California, containing data on precrisis employee counts, crisis reduction in revenues and employment, and medium-run closure risk. Second, we hand-collected a data set of Oakland small-business responses to the shelter-inplace order, codifying the details of the industry and the essential, sidewalk-facing, and open-closed interim status of the businesses. Third, we use foot-traffic data from SafeGraph, covering consumer visitation data from mobile devices. Finally, we use labor data for small businesses obtained from HomeBase.

In our empirical analyses, we estimate the effect of the logarithm of the number of precrisis workers on the 3 survival-capability mechanisms. Two general comments are in order about these analyses. First, we run the results against the continuous variable of workers, but we cast the economic magnitude inference in terms of nonemployers, microbusinesses (businesses defined to have 1-5 employees before the crisis), and enterprises (those with ex ante 6-50 employees). The differences between microbusiness and enterprises (although not using this

mass layoff, a plant closure, or a major relocation, but it applies only to employers having more than 100 employees. Similar small-business exemptions apply under state laws imposing analogous notice requirements to employers operating within a state. For instance, the California WARN Act exempts businesses that have employed fewer than 75 California employees in the past 12 months.

${ }^{2}$ Many nonemployers operate at a loss (Hurst and Pugsley (2011); see also Internal Revenue Service (IRS) 2017 data at https://www.irs.gov/statistics/soi-tax-stats-nonfarm-sole-proprietorship-statistics). These proprietors who operate at a loss may not view their businesses as failing. Moskowitz and Vissing-Jørgensen (2002) and Hurst and Pugsley (2011) show that nonemployers exhibit behavior consistent with the consumption of nonmonetary utility in the running of their businesses. 
labeling) have been previously noted in terms of growth rates in Haltiwanger, Jarmin, and Miranda (2013) and Decker, Haltiwanger, Jarmin, and Miranda (2014). As we will show graphically, the line of dividing a 5- versus 6-worker firm is not critical, yet the notion that worker-stable "Main Street" microbusinesses are different from firms oriented toward growth is important in the macroeconomic literature. Thus, we use terminology to make these categories distinct for mental accounting purposes.

The second general point is that we do not claim that our estimations are causally identified empirically, rather, just consistent with our model framework. We also hope to invoke personal intuition in analyzing this new topic of survival capabilities by using our caterer-taqueria-pizza restaurant story frame. We hope future research will build on our intuitive framings in accounting and storytelling to explore additional causal estimation of these insights.

Our first analyses test revenue resiliency by ex ante (log of) firm size. Within the Oakland survey, nearly $70 \%$ of businesses reported a drop of more than $40 \%$ in year-over-year revenues for Mar. 2020. We find statistically relevant, but small, differences based on firm size, after controlling for revenue-relevant characteristics, such as location, whether the business was essential under the county's shelter-in-place order, industry fixed effects, and year-over-year revenues for the prior month. Overall, revenue resiliency is low for nonemployers, then somewhat higher for microbusinesses, and thereafter lower again as ex ante employee counts increase. The differences are meaningful but economically small. Microbusinesses experience a revenue decline that is roughly $14 \%$ lower than that of the larger small businesses.

We obtain remarkably similar results when we use SafeGraph foot-traffic data as a measure of revenue-generating patrons. In a difference-in-difference estimation with firm fixed effects, we estimate that relative to January levels, enterprises and nonemployers experienced a $78.7 \%$ and $78.3 \%$ drop, respectively, in foot traffic in the weeks following the shelter-in-place order. Microbusinesses fared slightly better, experiencing a $74 \%$ decline, suggesting that microbusinesses were able to avoid roughly $6 \%$ of the drop felt by enterprises.

What these results on revenue resiliency do not explain is the mechanism of why revenue resiliency varies by firm size. We posit possible explanations. It is possible that microbusinesses either have a greater capacity to pivot revenue generation or have greater loyalty of workers. We offer further explanation of this possibility in the text, but we note that such intuition is consistent only with the result.

Our second series of analyses tests whether labor flexibility differs by firm size. Focusing first on the Oakland survey data, we find that layoffs of full-time workers and part-time workers had elasticities to firm size (based on precrisis employee headcount) of 0.127 and 0.172 , respectively, controlling for location effects, essential status, industry fixed effects, and Mar. 2020 revenue losses. Putting these estimates into the context of our growth categories of businesses, they indicate that enterprises laid off approximately $38 \%$ of full-time workers and $50 \%$ of part-time workers. In contrast, microbusinesses exhibited roughly half the labor flexibility of enterprises, laying off approximately $18 \%$ and $24 \%$ of their fulland part-time workers, respectively.

We supplement these survey estimates of labor flexibility using HomeBase data. In a differences-in-differences estimation with firm and week fixed effects, 
we estimate the elasticity of postcrisis employee counts and payrolls to firms' precrisis employee headcount, controlling for revenue declines. We find elasticities of postcrisis labor to precrisis worker counts ranging between -0.26 and -0.28 , nationally and in Oakland. Translating these findings into our classification of firms, we find that during the pandemic, enterprises were able to cut back payrolls $49.5 \%$, whereas microbusinesses cut back only $30.0 \%$, or $60 \%$ of the reduction of enterprises.

Overall, our intuition that labor flexibility is a central survival tactic for enterprises is more transparent in the data than was the case for our intuition regarding revenue resilience. Microbusiness employees are all core employees; thus, for a business to stay open and staffed during working hours, it is simply harder to scale down workers.

Third, we investigate the role of committed costs in a firm's survival across different-sized firms. We base our estimates on respondent's self-reported probability of having to close permanently, taking residual closure risk variation as a proxy for committed costs once we level firms on revenue resiliency and labor flexibility. We find that closure risk is increasing in worker counts. In particular, relative to microbusinesses and nonemployers, enterprises face a respective $10 \%$ and $20 \%$ higher closure risk as a result of committed costs. These results are consistent with larger small businesses incurring greater committed costs as they expand operations, but unlike labor, these costs are less flexible, making them a primary source of closure risk for growth-oriented small businesses. These findings are broadly consistent with the survey data from Alekseev et al. (2020), who report that in addition to reporting difficulties paying salary (24.1\%), survey respondents reported struggling to pay rent $(24.9 \%)$ and service debt commitments $(23.0 \%)$.

We next map these findings to the design of small-business disaster assistance, both in the context of COVID-19 and in other periods of local and national macroeconomic distress. Our mapping puts a framing on a set of simple intuitions. Working capital loan programs to small businesses (e.g., conventional disaster loans offered by the Small Business Administration (SBA)) require revenueresilience mechanisms to be at work, which, at least in the short term, would be most effective for microbusinesses and then nonemployers. Conversely, programs offering subsidies to restructure debt, leases, or other committed costs would be most effective in improving survival odds for larger enterprises. Lastly, labor-cost-oriented grant and subsidy programs would be most effective for microbusinesses and nonemployers, who cannot depend on labor flexibility for survival because the labor force consists of core employees.

Consider, for example, the landmark PPP implemented as part of the Coronavirus Aid, Relief, and Economic Security (CARES) Act in Mar. 2020. The PPP authorized the expenditure of nearly $\$ 610$ billion in small-business loans. As suggested by its name, PPP loans were intended to subsidize labor, and the original terms of the program provided that the loans could be forgiven entirely if a business spent at least $75 \%$ of loan proceeds to maintain precrisis payrolls in the first 8 weeks following loan disbursement. But given our findings regarding labor flexibility, this subsidy sits uncomfortably with the survival capabilities of larger enterprises, which may have little need for a labor subsidy given their ability to scale back labor to match reduced revenues. Consistent with this observation, 
Chetty et al. (2020) find that the PPP failed to spur employment among businesses receiving a PPP loan. Their sample, however, did not include microbusinesses, for which a labor subsidy may have been more useful under our framework.

To explore this possibility, we turn to the second Oakland survey, a follow-up survey conducted in June 2020 that focused specifically on the aid that Oakland small businesses had pursued, as well as their short- and medium-term projections for survival. Of particular interest is the utilization of PPP loans and the PUA authorized by the CARES Act. Both programs represent a labor subsidy insofar that they were intended to cover labor costs for employer and nonemployer businesses. As such, they should be especially useful for those businesses that continue operations but are limited in their ability to scale down labor costs.

Our setup to study the effects of the PPP and PUA on survival is subject to concerns about selection. However, with regard to the PPP, we are aided by the design of the Oakland survey and the evidence and insights in Granja et al. (2020) and BCGLSS (2020). The Oakland survey asked whether an owner applied for each program, allowing the answer to be "no"; "yes, successfully"; or "yes, unsuccessfully." Because there were little to no financial or economic eligibility criteria for the PPP (other than providing attestations), Granja et al.'s (2020) first stage test shows convincingly that the lack of success largely results from bank frictions. BCGLSS (2020) similarly demonstrate that for the first wave of PPP applications, an applicant's likelihood of approval was largely due to the size of the bank through which the applicant applied. Thus, we can use the applying-for-thePPP variables to control for selection and study the effect of the PPP under the idea that the Granja et al. (2020) insight holds in our sample.

We find results consistent with the intuition in our framework and the laborflexibility results. Relative to firms that were unsuccessful in applying for PPP funding, those that successfully applied reported a $20.5 \%$ greater probability of being able to survive beyond 6 months. This result, however, is confined to microbusinesses, consistent with these firms' inflexible labor structures. Because of the important role of these businesses within the national economy, this finding suggests that the PPP has been beneficial for stakeholders in the vast majority of small businesses in the country. For instance, according to 2015 census data, $92.9 \%$ of businesses had fewer than 20 employees, and 17\% of employment was in businesses with under 20 employees. Nonemployer owners who utilized the PUA also reported a lower likelihood of having to close their businesses in the short term but not the medium term, consistent with nonemployers using this short-term labor subsidy (which was originally set to expire in July 2020) to avoid searching for alternative sources of personal income, thus averting an immediate closure of their establishments.

We contribute to the literature by examining how firm size can induce small businesses to pursue heterogeneous survival tactics when confronted with an adverse macroeconomic shock. In this regard, we build off the growing literature examining the role of firm size (measured by employment) in the growth and risk of small businesses (Davis, Haltiwanger, and Schuh (1996), Davis, Haltiwanger, Jarmin, Krizan, Miranda, Nucci, and Sandusky (2009), Haltiwanger et al. (2013), Decker et al. (2014), and Mayer, Siegel, and Wright (2018)). By focusing on small businesses faced with a macroeconomic shock, however, we illustrate the unique ways in which firm size also matters to a perspective on firm survival and policy. 
Both our framing and our empirical findings are also consistent with a growing body of research exploring the effect of COVID-19 on small businesses and their heterogeneous survival responses. In addition to the literature noted previously documenting patterns of distress within the sector, Kim et al. (2020) find that the smallest businesses began recovering revenues faster than the larger small businesses in their sample. Using Norwegian data on small businesses, Alstadsæter, Bjørkheim, Kopczuk, and Økland (2020) provide simulations that underscore the first-order importance of labor flexibility for firm survival for most small businesses, as well as differentials across small businesses in the utility of this tactic in surviving the pandemic. Alekseev et al. (2020) examine differences in firms' ability to reopen, finding heterogeneities in prospects of profitability and the ability to service fixed costs, as well as differences across owner gender and the ability to work remotely. BCGLSS (2020) explore differentials in the impact of the PPP on firms' perception of survival and find it to be most effective for firms with low fixed expenditures, a finding that echoes our conclusion that a labor subsidy is insufficient for aiding a growing business that has incurred significant committed costs. Our empirical frame and findings are thus consistent with the findings of this growing literature and underscore the importance of firm size in explaining why firms of different sizes should be expected to experience different financial challenges and, relatedly, why they would be drawn to different support policies. $^{3}$

Our findings have critical implications for the design of small business assistance programs, especially when combined with the established welfare effects of different-sized small businesses. Decker et al. (2014) show that among small businesses, only those with more than 10 employees create future job growth past the formative years. That the PPP was most effective as a survival program for nonemployers and microbusinesses may accordingly concern those who saw the program as an aid to future job growth.

Conversely, the PPP might be assessed more favorably among those viewing the program through a welfare lens that prioritizes the needs of community economic stakeholders. The evidence in Hurst and Pugsley (2011) and Austin, Glaeser, and Summers (2018) documents how nonemployers and microbusinesses critically support local communities through the maintenance of vibrancy in commercial districts. Community vibrancy directly maps to welfare through spatial spillovers to governments and other community stakeholders through commercial and residential property tax bases (Alm, Buschman, and Sjoquist (2014), Shoag and Veuger (2018), and Tsivanidis and Gechter (2020)) and through support for females and minority entrepreneurship (SBA (2018)). Thus, taken in this light, the proportion of PPP funds tapped by microbusinesses and nonemployers might have induced large welfare gains. Such a finding would

\footnotetext{
${ }^{3}$ A separate line of research additionally examines how firm survival during COVID-19 is also associated with the race and ethnicity of an establishment's proprietor. For instance, Fairlie (2020) finds that African American business owners experienced a drop of $26 \%$ in business activity from preCOVID-19 levels compared with only a 11\% drop for White business owners by May 2020. Aside from the effectiveness of support policies on different-sized establishments, this literature raises important policy questions relating to the equitable distribution of small-business aid, which are also considered in Erel and Liebersohn (2020).
} 
provide a counterpoint to prominent arguments for letting existing unemployment insurance nets and creative destruction work in the market in an effort to save funds for the revival of growing enterprises, rather than subsidizing the survival of all small businesses (Rajan (2020)). In short, designing smallbusiness assistance with a single-minded focus on job creation risks creating zombie Main Streets and a greater geographic concentration of commerce and wealth (Austin et al. (2018)).

To make more progress on these welfare trade-offs is beyond the scope herein. Yet sound small-business policy points to the need to account for the divergent welfare effects of supporting different sizes of small businesses through periods of macro distress. For the same reasons, policy must also consider how the heterogeneities in small-business survival capabilities map to the design of specific small-business assistance programs. ${ }^{4}$ Our contribution is to provide that mapping.

The rest of the article is organized as follows: In Section II, we present our framework for small-business survival capabilities. We describe our data in Section III and provide summary statistics for each of the 4 data sets that comprise it. Our empirical results are reported in Section IV. Section V examines the policy implications of our findings with respect to the design of small-business assistance programs. Section VI reports on whether the PPP and PUA affect medium-term survival in Oakland, building off the policy frame. Section VII concludes.

\section{Frame}

We lay out a simple frame of the components of firm-level cash flows to fix ideas. We define cash flows $\pi$ as net revenues $(r)$ minus labor costs $(l)$ and committed other costs $(c)$ :

$$
\Pi=r-l-c,
$$

where net revenues $(r)$ is revenues minus the inventory costs of goods sold. We consider a negative macro shock $R^{-}$to the economy, which imposes a loss of a unit of net revenue on average for small businesses but with variance across firms. We are interested in the survival of a firm, defined as the maintenance of positive cash flows from the existing cash-flow position of the firm following the macro shock, or:

$$
\text { survival: }=\pi+\frac{d \pi}{d R^{-}}>0 \text {. }
$$

\footnotetext{
${ }^{4}$ In the context of the PPP, for instance, the need to consider the heterogeneities in small-business survival capabilities was made evident shortly following the launch of the program. In particular, a chorus of small-business owners argued that the PPP forgiveness requirement that $75 \%$ of the loan amount be spent on payroll was ill-suited for their survival plans, causing them to pass on the program (Freedman (2020)). In response, Congress amended the program to decrease the required payroll spend to $60 \%$ of loan proceeds and to allow it to be accomplished over a 24 -week period rather than an 8 -week period.
} 
Taking the derivative and allowing for labor to scale with revenues or to be directly affected by the shock, we have the survival condition as follows:

$$
\underbrace{\left(r+\frac{d \mathrm{r}}{d R^{-}}\right)}_{\text {revenue grit }}-\underbrace{\left(l+\frac{\partial l}{\partial r} \frac{d r}{d R^{-}}+\frac{d l}{d R^{-}}\right)}_{\text {labor flexibility }}-\underbrace{\left(c+\frac{d \mathrm{c}}{d R^{-}}\right)}_{\text {committed costs }}>0 .
$$

Survival is a function, first, of the ability of firms to exhibit revenue resiliency, preserving as much of ex ante revenue as possible, such as by restructuring operations (e.g., working remotely, pivoting to pick-up or delivery services, Facebook campaigns to alert customers of continued operations, etc.). Next, survival is a function of labor-cost flexibility, which incorporates how elastic a firm's labor cost is to revenue as well as direct labor effects from the macro shock. Finally, survival is a function of the size of the committed costs and the ability to restructure costs following the shock $R^{-}$.

In our empirical analysis, we assume that these 3 survival tactics are capabilities of firms in the sense that firms will optimally do whatever they can to adjust to the macro shock. We estimate these survival capabilities with the lens of looking at how they vary by firm size, focusing on our 3 categories of nonemployers, microbusinesses, and enterprises, all within the industry sector.

We then map the results to inferences concerning policies aimed at supporting small businesses during periods of macro distress. In particular, we consider 3 sets of program features in terms of how they relate to our frame:

Subsidized Working Capital Loans. Programs such as Economic Injury Disaster Loans (EIDLs) offered through the SBA provide subsidized loans to businesses struggling with natural disasters. These programs impose conditions on recipients to ensure that loan proceeds are used to support working capital in rebuilding revenues. Recipients of EIDLs, for instance, are prohibited from using loan proceeds to refinance long-term debt or expand operations. As summarized by the SBA, EIDLs are for entities that are "ready to 'restart' their operations once circumstances allow" (SBA (2020)). These subsidized working capital loans should therefore be most useful for those firms that have revenue resiliency among their survival capabilities.

Labor-Cost Grants and Subsidies. Programs such as the PPP and PUA (as used by nonemployers as income substitution) provide a subsidy to labor costs, conditional on labor remaining in place. Payroll tax holidays (e.g., on the employer match for Social Security payroll taxes, as was done by President Carter in the Jobs Tax Credit in the Tax Reduction and Simplification Act of 1977 and more recently in the CARES Act) would also subsidize continuing employment. These policies will be effective when most workers are core-function employees but may be less

\footnotetext{
${ }^{5}$ Importantly, this framework omits a reliance on savings, based on empirical findings that small businesses maintain very little working capital or cash reserves to weather an adverse shock to revenue. For instance, during the COVID-19 crisis, estimates from the U.S. Census Small Business Pulse Survey show that only $25 \%$ of firms had enough cash on hand to cover 3 months of operations at the end of May 2020 (U.S. Census (2020); see also BBCGLS (2020)).
} 
efficient and attractive for small businesses endowed with high labor flexibility that they use to survive business-cycle downturns.

Lease or Debt Payment-Restructuring Subsidies. Governments might choose to implement policies aimed at reducing the committed cost burdens on small businesses akin to the Home Affordable Modification Program (HAMP) applied to households and lenders during the Great Recession, whereby the government subsidizes the lender (or leaseholder) to restructure the obligation. In the context of small businesses, these programs may take the form of providing government grants that can be used to offset commercial lease costs. Facilitating small-business bankruptcy reorganizations would also have the effect of providing small businesses with leverage to restructure large committed costs. We provide examples of both forms of these programs in Section V. Either form of program will be especially relevant for small businesses whose survival will depend on their ability to restructure large committed costs incurred prior to the macro shock.

\section{Data and Summary Statistics}

A primary challenge confronting research about small businesses concerns the unavailability of firm performance data. We address this challenge through a multistep data-collection process that exploits our ability to collect real-time data as small businesses began to experience the impact of the COVID-19 economic shutdown. These real-time data come from the following 4 sources.

\section{A. City of Oakland Small-Business Survey}

In early Mar. 2020, well before Alameda County (the county where Oakland sits) imposed its shelter-in-place order, the City of Oakland constructed a survey to elicit information from its small-business community about resiliency during the COVID-19 pandemic. The city's survey went live 3 days prior to the Mar. 16 announcement of the county's shelter-in-place order. Our core analyses focus on responses submitted between Mar. 13, 2020, and Apr. 1, 2020. Our sample starts with 1,088 surveys. After filtering out 37 businesses with more than 50 employees, 19 purely online businesses, and 18 nonprofits, we have a sample of 1,014 firms. Based on census data, we estimate that the survey captured $11 \%-15 \%$ of the city's small businesses. ${ }^{6}$

Table 1 reports the summary statistics from the City of Oakland survey. Panel A reports the sample statistics regarding employment, covering the following variables:

\footnotetext{
${ }^{6}$ According to the 2017 County Business Patterns from the U.S. Census Bureau, there were nearly 14,000 private and government establishments in Oakland's zip codes. Using this number directly would imply that our sample captures $7.8 \%$ of Oakland's businesses, but this is too conservative because the census total i) includes businesses with up to 500 employees (and our survey is for small businesses); ii) assumes that small businesses have only one establishment; iii) includes non-revenuegenerating registered businesses; and iv) includes schools, government offices, and other nonbusiness organizations.
} 
NONEMPLOYER: An indicator for the firm reporting no employees. MICROBUSINESS: An indicator for the firm reporting 1-5 employees. ENTERPRISE : An indicator for the firm reporting 6-50 employees. PRECRISIS_EMPLOYEES : Full- and part-time employees prior to Mar. 2020.

PERCENTAGE_CHANGE_JOB_LOSSES: Full- and part-time positions lost early in the shutdown, relative to reported precrisis full- and parttime positions.

A quarter of the sample of Oakland small businesses are nonemployers, $43 \%$ are microbusinesses, and $32 \%$ are enterprises. The mean (median) employee count is 6.5 (2) for all small businesses and 8.7 (4) for businesses excluding the nonemployers. Of these jobs, $17.7 \%$ were already lost on average in the first weeks of the shelter-in-place order.

Panel B of Table 1 reports statistics on reported revenues, covering the following variables:

DECLINING: Whether or not the business was ex ante declining, defined as year-over-year (YoY) decline in gross receipts as of Feb. 2020.

PERCENTAGE_CHANGE_RECEIPTS : Reported percentage change in YoY gross receipts as of Mar. 2020 based on a firm's selection of 1 of 6 ranges.

Approximately half of all respondents indicated a decline in YoY revenue as of Feb. 2020, the month prior to the shelter-in-place order. We use this indicator variable as our proxy for indicating whether a firm's financial distress predated the U.S. COVID-19 crisis. The fact that half of small businesses might have negative growth is consistent with the results in Decker et al. (2014) and Hurst and Pugsley (2011) concerning the nongrowth nature of most small businesses. Also in Panel B of Table 1, we report the distribution of gross receipts YoY as of Mar. 2020. By early March, businesses were severely affected, first by self-imposed staying out of public spaces and then, on Mar. 16, by the county ordinance. This shows up in the distribution in Panel B, where $69 \%$ of respondents report a YoY decline of over $40 \%$ for March.

In Panel C of Table 1, we report the distribution to the response on closure risk, defined as follows:

CLOSURE_RISK: Whether the small-business owner responded that he or she was "very concerned" about the risk of closure, "somewhat concerned," or "not concerned."

Overall, $73 \%$ of respondents were very concerned about closure, and only $4 \%$ were not concerned.

As part of this survey, the City of Oakland subsequently conducted a follow-up survey completed by nearly 300 of the small businesses. We examine this follow-up survey in Section V. 
City of Oakland COVID-19 Survey of Small Businesses: Summary Statistics All data in Table 1 are from the City of Oakland COVID-19 survey of small businesses. Our sample is from Mar. 13, 2020, to Apr.
1,2020 . As reported in Panel A, the NONEMPLOYER, MICROBUSINESS, and ENTERPRISE classifications are indicator
variables dividing the sample into those with no employees, those with 1-5 employees, and those with $6-50$ employees,
respectively. PRECRISIS_EMPLOYEES is the number of employees reported in early March (precrisis). The smaller sample in
Panel A, 761 firms, includes those with positive employment. For this sample, we know the existing base of part-and full-time
employees and the jobs lost. Panel B presents two pictures of gross receipts. First is whether the business is declining in gross
receipts (DECLINING), defined as reporting the year-over-year (YoY) receipts as of Feb. 2020 as being in decline relative to
2019 . A smaller sample responded to the question as to the declines in March at the initial shelter-in-place order. The survey
asked owners to report their gross receipts in March YoY from Mar. 2019 (PERCENTAGE_CHANGE_RECEIPTS). Panel C
presents closure-risk responses. In particular, the survey respondents were asked how concerned they were about closing
the business, responding in the categories listed.

Panel A. Employment

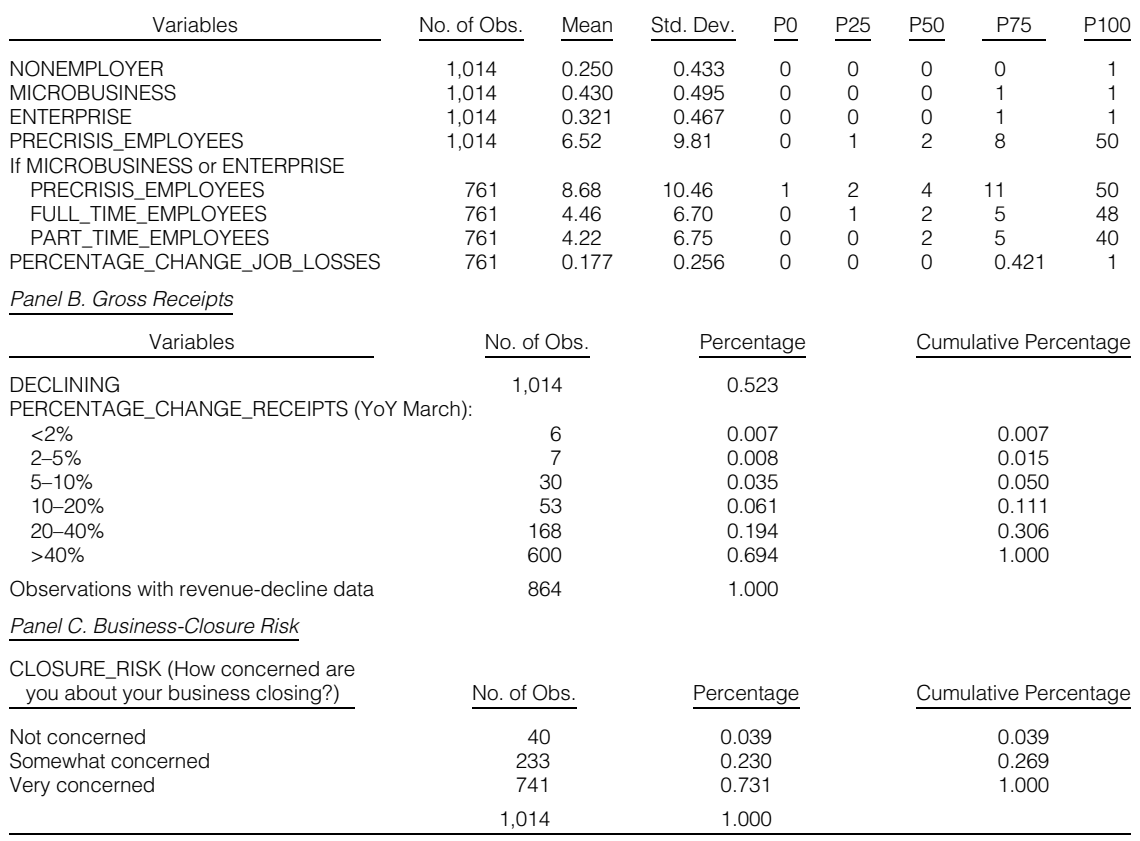

\section{B. Hand-Collected Information on Small-Business Operations}

We obtain additional operating data on these businesses from manual firm-byfirm Internet searches conducted between Apr. 24, 2020, and May 3, 2020 - the day on which Alameda County permitted certain outdoor businesses to recommence operations on a limited basis. We began these manual searches on Google Maps. Companies, particularly street-facing companies, had a large incentive to keep their Google Maps status updated, and businesses informed us that Google aggressively solicited each establishment for this information. We additionally searched for the company website and other Internet sources of information to determine the operating status for each survey company. 
For each business, we coded the following variables:

INDUSTRY: Narrowly defined industry.

MAIN_STREET: An indicator for a business being on a street-facing location (on "Main Street").

ESSENTIAL: Whether the business constitutes an "essential business" under Alameda County's shelter-in-place order (e.g., grocery stores, lumber and repair, pharmacies, and physician offices).

Panel A of Table 2 breaks down the distribution of industries and provides detailed examples of the type of businesses in each category. Panel B reports that twothirds of the sample consists of street-facing businesses, and a third provide their goods and services at a home or at an office that is not street-facing. We coded $11 \%$ of respondents to be deemed essential businesses under the shelter-in-place rules.

TABLE 2

\section{Oakland Manual Data Collection: Summary Statistics}

Table 2 presents the manual lookup data for the sample of businesses in the City of Oakland COVID-19 survey. We manually coded all fields (industry, location, whether the business is essential under Alameda County's shelter-in-place order, and outcome status) using a 2-step process. First, we looked up the establishment in Google Maps. Second, we went to the business's website (always) and other Internet sites where information might be available (if necessary), including Yelp and local blogs listing closures. In Panels A, B, and C, we show the distribution by industry categories (Panel A), location and whether the business is an essential business that is permitted to remain open per state regulations (Panel $B$ ), and the interim status of the business (Panel C). The interim outcome is the status of the business during the last week of Apr. 2020, immediately before reopening began in the county. The sample size is reduced because we are unable to categorize many professional services (e.g., lawyers and advertising agencies) that lacked updates on any information sites.

Panel A. Industry Classification

\begin{tabular}{|c|c|c|}
\hline Industry & No. of Obs. & Percentage \\
\hline BUSINESS_SERVICES & 82 & $8.1 \%$ \\
\hline $\begin{array}{l}\text { CONSTRUCTION/ } \\
\text { MANUFACTURING/NENUE }\end{array}$ & 95 & $9.4 \%$ \\
\hline FITNESS/GYM/WELLNESS & 86 & $8.5 \%$ \\
\hline MEDICAL_OFFICES & 38 & $3.7 \%$ \\
\hline PERSONĀL_SERVICES_HOME & 28 & $2.8 \%$ \\
\hline PERSONAL_SERVICES_SHOP & 75 & $7.4 \%$ \\
\hline PROFESSIONAL_SERVICES & 206 & $20.3 \%$ \\
\hline RESTAURANT & 156 & $15.4 \%$ \\
\hline RETAIL & 144 & $14.2 \%$ \\
\hline \multirow[t]{2}{*}{ SALON } & 104 & $10.3 \%$ \\
\hline & 1,014 & $100 \%$ \\
\hline
\end{tabular}

Catering, industrial cleaning, printing, photography, technology Construction, entertainment venues, event spaces, parking lots, housing, manufacturing, wholesale trade Fitness centers, gyms, massage, acupuncture Chiropractic, dentist, optical, physical therapy, psychology Home repair, landscape, pet walking, realty Auto repair, car wash, child care, education, laundry, tattoo Architects, consultants, designers, engineers, lawyers Restaurants

Retail shops

Salons, barbers

Panel B. Commerce Location and Essential Designation

Variables

MAIN_STREET

NON_MAIN_STREET (at a venue, home, or offsite)

ESSENTIAL

NONESSENTIAL

\begin{tabular}{c} 
No. of Obs. \\
\hline 674 \\
340 \\
1,014 \\
112 \\
902 \\
1,014
\end{tabular}

Percentage

$66 \%$

$34 \%$

$100 \%$

$11 \%$

$89 \%$

$100 \%$

Cumulative

No. of Obs.

$\underline{\text { Percentage }}$ Percentage

Panel C. Interim Outcome

STATUS

PERMANENTLY_CLOSED (or lacking ongoing concern signal)

TEMPORARILY_CLOSED

TRYING

OPEN

\begin{tabular}{lll}
159 & 0.192 & 0.192 \\
211 & 0.255 & 0.447 \\
172 & 0.208 & 0.655 \\
285 & 0.345 & 1.000 \\
827 & 1.000 & \\
\hline
\end{tabular}


Panel $\mathrm{C}$ of Table 2 reports the operating status of the survey respondents, defined as follows:

STATUS: The hand-coded operating status of the business at the time of the search, coded among the following: PERMANENTLY_CLOSED (or lacking ongoing concern signal), TEMPORARILY_CLOSED, TRYING, and OPEN.

Firms classified as TRYING (21\%) indicate those firms that were not permitted to operate under the shelter-in-place order but nevertheless conducted operations under alternative arrangements or reduced-revenue models. For example, this class of businesses might include a restaurant that operated on a limited take-out/delivery basis or a yoga studio that operated remotely through video conferencing. The TEMPORARILY_CLOSED status, which was actively pursued by Google Maps to provide its customers with accurate data on the availability of businesses, accounted for approximately $26 \%$ of the sample. We overrode Google Map's TEMPORARILY_CLOSED to be TRYING if the business website indicated that it was operating in some form to generate revenues; most TRYING businesses were marked "Temporarily Closed" by Google, except for restaurants, which were marked "Take-Out Only" or "Delivery Only" (or both). The PERMANENTLY CLOSED (or lacking ongoing concern signal) businesses (19\%) were a combination of those businesses that were explicitly marked as permanently closed by Google Maps and those businesses that showed no sign of any ongoing business on their Web pages and did not indicate that they were temporarily closed.

In Figure 1, we plot the status by industry in pie charts to underscore the economic challenge to survey respondents posed by the COVID-19 pandemic. Temporary closures were especially high within the retail, fitness/salon/ wellness, and construction sectors. Only in the medical, professional services, and personal services sectors was the OPEN category the dominant classification. In contrast, the TRYING classification was prevalent among restaurants, fitness, and retail.

\section{HomeBase}

Our third set of data comes from HomeBase, a company handling workplace scheduling and payroll management that caters primarily to small businesses. ${ }^{7}$ The HomeBase data include anonymized data for an establishment's weekly employee headcount and, for some firms, reported weekly wages paid to some or all employees. We filter the HomeBase data to all business establishments that have a U.S. zip code and a disclosed industry and that have 50 or fewer average employees between Jan. 1, 2020, and Feb. 15, 2020.

In Panel A of Table 3, we report summary statistics for this sample of HomeBase establishments. Our primary interest is in the following weekly measures:

\footnotetext{
${ }^{7}$ These data have been made available by HomeBase for researchers examining the labor-market impact of COVID-19 and have been a primary source of data for examining overall employment trends within the small-business sector during the COVID-19 economic crisis (see, e.g., Bartik, Bertrand, Lin, Rothstein, and Unrath (2020)).
} 


\section{FIGURE 1}

\section{Interim Outcome Status by Industry}

Figure 1 depicts the interim outcomes via the manual search data for the City of Oakland firms as of the last week of Apr. 2020 "Trying" indicates that the business is working on a reduced- or alternative-revenue model and is otherwise temporarily closed. "Permanently Closed" indicates that the business is either marked permanently closed on Google Maps, the company website, or Yelp or the business shows no information as to closure being a going concern.

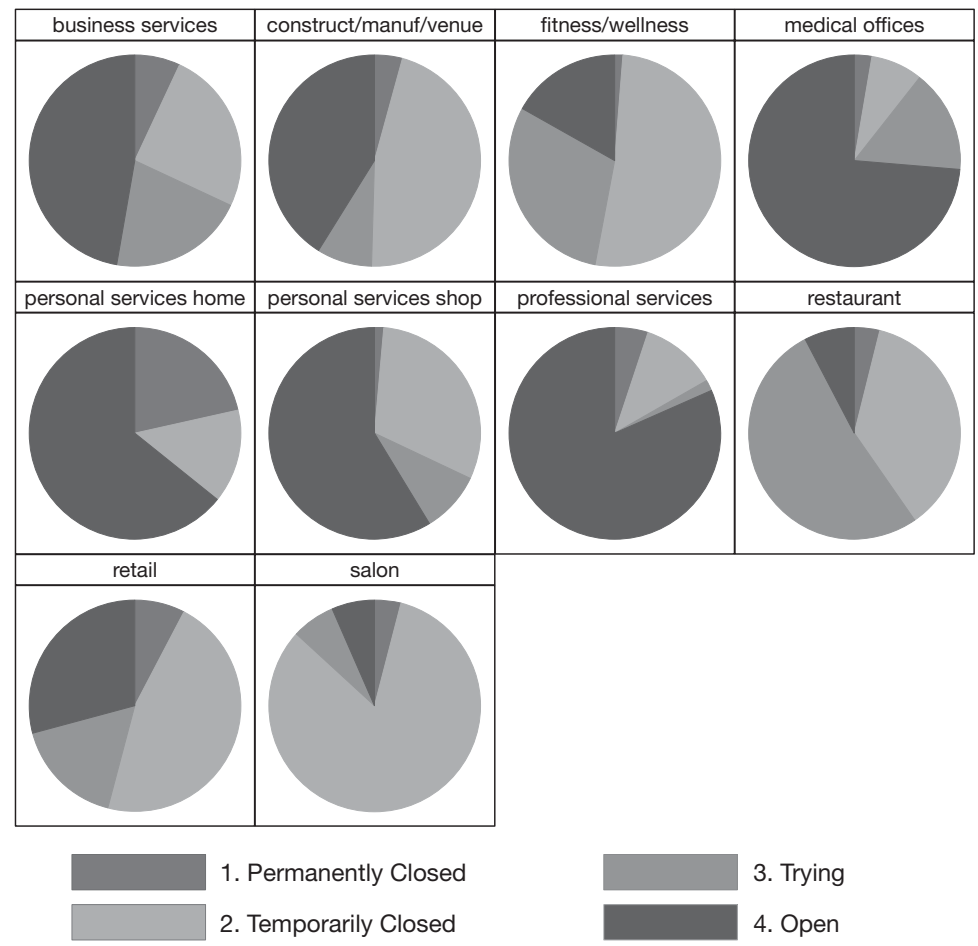

HEADCOUNT: Weekly full- and part-time employees (regardless of whether wages are disclosed) per location.

PAYROLL: Weekly wages paid to employees for whom wages are disclosed.

Columns 1-4 indicate that the HomeBase firms within our sample had a mean (median) employee headcount of 7.6 (5.5) during the period from Jan. 1, 2020, to Feb. 15, 2020. Not surprisingly, employee headcount varied by industry, ranging from a low of 4.34 (3) among establishments in the beauty and personal care industry to a high of 9.21 (7.3) within the food and drink industry. In columns $5-8$, we similarly present summary data concerning total weekly wages paid for those establishments that reported the weekly wages paid to one or more employees over the same period. Among these firms, mean (median) precrisis wages paid per week were roughly $\$ 2,400(\$ 1,500)$. Across industries, beauty and personal care establishments were the lowest paying within the sample, whereas transportation establishments paid the most, presumably reflecting the higher hourly wage rates paid by these latter firms. 
TABLE 3

HomeBase Employee Data and SafeGraph Foot-Traffic Data: Summary Statistics

Panel A of Table 3 presents summary statistics for the sample of small businesses provided by HomeBase, tabulated separately by HomeBase industry. Columns 1-4 present mean and median employee headcount during the period from Jan. 1, 2020, to Feb. 15, 2020. Columns 5-8 present statistics for total weekly wages during this same time period for those firms within HomeBase that reported wages for some or all employees. Panel B presents summary statistics by coded industry for the variable FOOT_TRAFFIC for 268 small businesses in the Oakland survey that could be matched to a point of interest (POI) within the SafeGraph data set. FOOT_TRAFFIC is defined as reported visits per day to a POI between Jan. 1, 2020, and Mar. 15, 2020, scaled by the number of devices observed by SafeGraph in Alameda County per 100,000 residents. This is a standard scaling recommended per SafeGraph documentation.

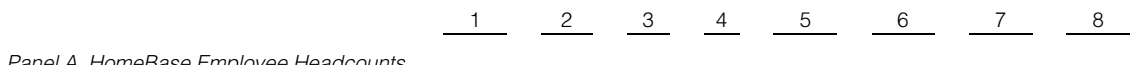

Panel A. HomeBase Employee Headcounts

\begin{tabular}{|c|c|c|c|c|c|c|c|c|}
\hline \multirow{2}{*}{ HomeBase industry } & \multicolumn{4}{|c|}{ HEADCOUNT } & \multicolumn{4}{|c|}{ PAYROLL } \\
\hline & $\begin{array}{l}\text { No. of } \\
\text { Obs. }\end{array}$ & Mean & $\begin{array}{l}\text { Std. } \\
\text { Dev. }\end{array}$ & P50 & $\begin{array}{l}\text { No. of } \\
\text { Obs. }\end{array}$ & Mean & $\begin{array}{l}\text { Std. } \\
\text { Dev. }\end{array}$ & P50 \\
\hline BEAUTY_\&_PERSONAL CARE & 417 & 4.34 & 4.29 & 3.0 & 235 & $\$ 1,093$ & $\$ 1,344$ & $\$ 692$ \\
\hline CHARITIES_EDUCATION_\&_MEMBERSHIP & 1,430 & 8.55 & 8.16 & 6.0 & 1,013 & $\$ 2,084$ & $\$ 3,298$ & $\$ 1,168$ \\
\hline FOOD_DRINKK & 23,159 & 9.21 & 7.41 & 7.3 & 16,761 & $\$ 2,491$ & $\$ 2,742$ & $\$ 1,731$ \\
\hline HEALTH_CARE_AND_FITNESS & 3,934 & 5.57 & 5.44 & 4.0 & 2,520 & $\$ 2,086$ & $\$ 2,782$ & $\$ 1,189$ \\
\hline HOME_AND_REPAIR & 579 & 5.10 & 5.82 & 3.2 & 409 & $\$ 2,574$ & $\$ 3,290$ & $\$ 1,753$ \\
\hline LEISURE_AND_ENTERTAINMENT & 936 & 7.91 & 7.95 & 5.3 & 735 & $\$ 2,038$ & $\$ 2,523$ & $\$ 1,175$ \\
\hline OTHER & 4,189 & 7.09 & 7.48 & 4.5 & 2,972 & $\$ 2,725$ & $\$ 4,522$ & $\$ 1,468$ \\
\hline PROFESSIONAL_SERVICES & 1,986 & 5.07 & 5.88 & 3.2 & 1,333 & $\$ 2,470$ & $\$ 4,817$ & $\$ 1,183$ \\
\hline RETAIL & 8,649 & 5.46 & 5.13 & 4.0 & 5,962 & $\$ 2,397$ & $\$ 3,464$ & $\$ 1,354$ \\
\hline TRANSPORTATION & 373 & 6.79 & 7.43 & 4.2 & 261 & $\$ 3,577$ & $\$ 4,741$ & $\$ 1,859$ \\
\hline UNKNOWN & 4,797 & 7.19 & 6.46 & 5.2 & 3,262 & $\$ 2,157$ & $\$ 2,797$ & $\$ 1,282$ \\
\hline All & 50,449 & 7.60 & 6.98 & 5.5 & 35,463 & $\$ 2,413$ & $\$ 3,197$ & $\$ 1,510$ \\
\hline Panel B. SafeGraph Foot Traffic & & & & & & & & \\
\hline & & & & FOOT & TRAFFIC & & & \\
\hline INDUSTRY & $\begin{array}{l}\text { No. of } \\
\text { Obs. }\end{array}$ & Mean & $\begin{array}{l}\text { Std. } \\
\text { Dev. }\end{array}$ & & $\underline{\mathrm{P} 25}$ & $\underline{\mathrm{P} 50}$ & P75 & $\underline{\mathrm{P} 100}$ \\
\hline BUSINESS_SERVICES & 5 & 3.89 & 2.32 & & 2.55 & 3.42 & 4.82 & 7.35 \\
\hline $\begin{array}{l}\text { CONSTRUCTION/MANUFACTURING/ } \\
\text { VENUE }\end{array}$ & 19 & 6.54 & 5.54 & & 1.31 & 5.01 & 11.64 & 16.15 \\
\hline FITNESS/GYM/WELLNESS & 28 & 4.83 & 4.65 & & 1.23 & 3.37 & 7.48 & 18.25 \\
\hline MEDICAL_OFFICES & 4 & 0.85 & 0.43 & & 0.56 & 0.74 & 1.14 & 1.46 \\
\hline PERSONĀL_SERVICES_HOME & 14 & 5.73 & 5.50 & & 1.96 & 4.85 & 6.63 & 21.47 \\
\hline PERSONAL_SERVICES_SHOP & 7 & 5.12 & 7.51 & & 0.68 & 2.54 & 4.20 & 21.85 \\
\hline RESTAURANT & 114 & 7.55 & 8.31 & & 3.31 & 5.37 & 8.46 & 59.68 \\
\hline RETAIL & 67 & 4.90 & 4.45 & & 1.23 & 4.00 & 6.53 & 17.38 \\
\hline SALON & 10 & 2.52 & 3.00 & & 0.89 & 1.46 & 3.19 & 10.50 \\
\hline Total & 268 & 6.02 & 6.63 & & 1.83 & 4.17 & 7.48 & 59.68 \\
\hline
\end{tabular}

In Figure 2, we plot the distribution of our sample of HomeBase establishments by state. California, Texas, and Florida claim roughly $16 \%, 10 \%$, and $9 \%$ of establishments, respectively.

\section{SafeGraph Foot-Traffic Data}

Our final data set is data on foot traffic in establishments from SafeGraph for Jan. 1, 2020, to Apr. 30, 2020. SafeGraph covers mobile locations for over 30 million individuals using cell-phone tracking information that these individuals have consented to share pursuant to one or more applications installed on their mobile devices. SafeGraph overlays this tracking data to 5 million U.S. establishments or "points of interest" (POIs) based on the actual location and shape of the POI (i.e., its polygon) rather than its address, thus allowing SafeGraph to identify each instance when an individual visits a POI. 
FIGURE 2

Distribution of HomeBase Establishments by State

Figure 2 reports the percentage of establishments by state across all establishments within our sample of HomeBase establishments. The reported state of location is provided by HomeBase.

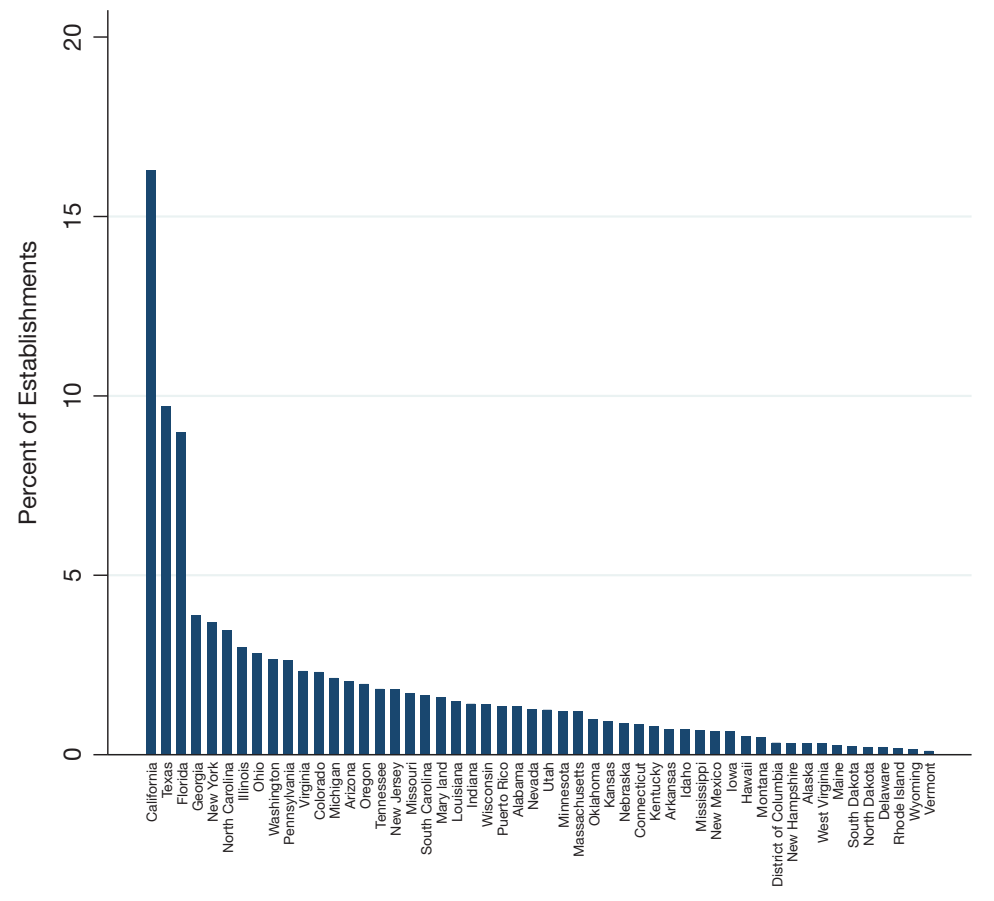

Figure 3 maps the mean number of devices during this period for all counties in the continental United States and within California. SafeGraph tracked over 1,000 devices in over half of all counties. In Alameda County, the focus of our study, SafeGraph tracked over 50,000 devices, allowing us to use these data as a proxy for the revenue of small businesses, particularly for "Main Street" businesses, whose cash flow is likely to depend on foot traffic.

We cannot use the data to infer dollars of revenue per se because different store types have different conversion rates of customers to revenues. Yet we can use foot traffic to infer the revenue shock, using firm fixed effects, following the approach of investigative journalists and policy makers examining the impact of the COVID-19 crisis on consumers. ${ }^{8}$ Figure 4 illustrates the feasibility of this approach, focusing on select industries within Alameda County: restaurants, electronics and appliance stores, fitness/sports centers, and grocery stores. We standardize visits by observed daily devices and calculate the moving average over the preceding 7-day period. Plotted is the moving average over time relative to that for Jan. 8, 2020. All businesses suffered a significant drop in foot traffic following the shelter-in-place order, which is represented by the dashed vertical line on Mar. 16. The primary

\footnotetext{
${ }^{8}$ See, for example, Megan Cerullo, "Phone Data Show Consumers Avoiding Stores, Restaurants as COVID Surges,” CBS News, July 2, 2020, available at https://www.cbsnews.com/news/cell-phonedata-show-consumers-avoiding-stores-as-covid-19-cases-surge/.
} 


\section{FIGURE 3}

Distribution of SafeGraph Devices Nationally and Within California

Figure 3 presents, by county, the mean number of mobile devices observed by SafeGraph between Jan. 1, 2020, and Apr. 30, 2020. Graph A presents national data, and Graph B provides an enlarged figure for California (Alameda County is shown in black).

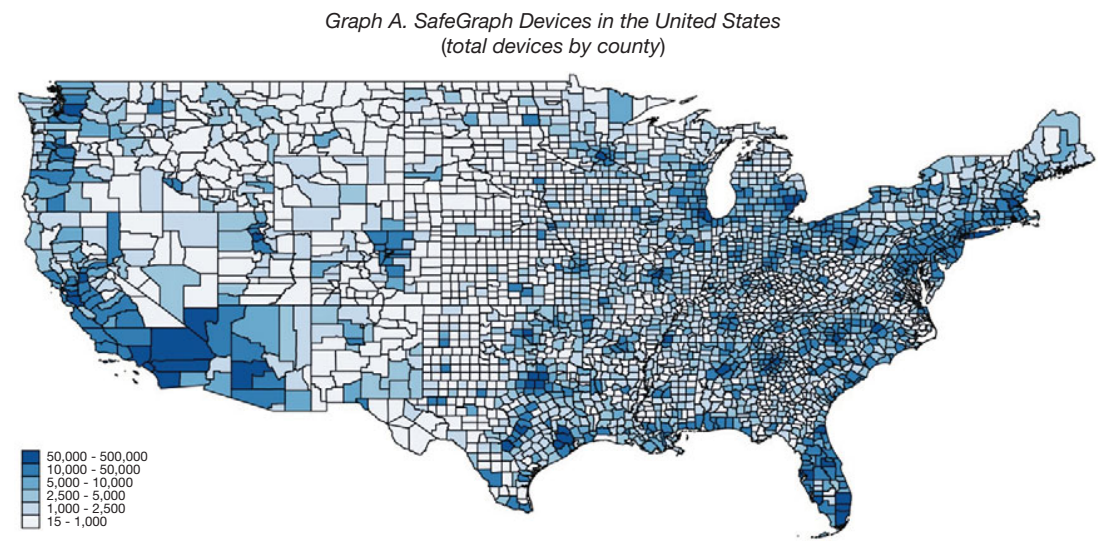

Graph B. SafeGraph Devices in California (total devices by county)

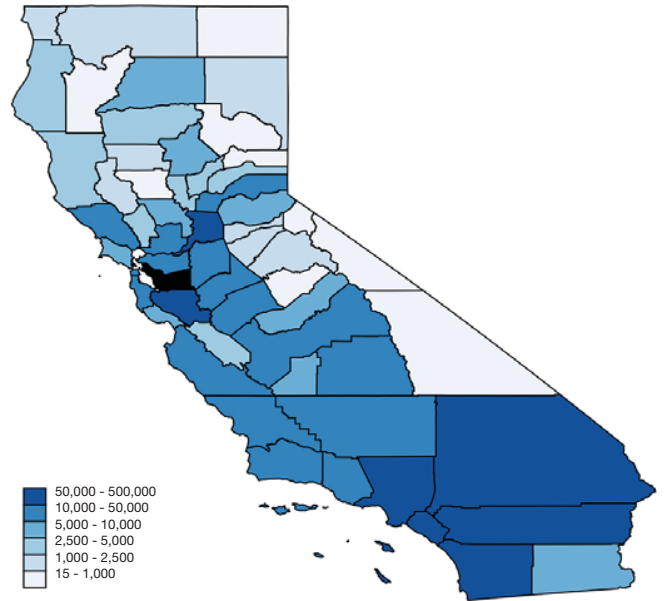

exception relates to the surge in grocery store foot traffic in the days immediately following the announcement of the order as residents flooded grocery stores.

We match the Oakland small-business survey respondents to the SafeGraph POI data set by business name, enabling us to assess directly the extent to which a business's foot traffic was affected by Alameda County's shutdown in economic activity. These foot-traffic data span from Jan. 1, 2020, to Apr. 30, 2020; however, we drop the period of closing down in late March (Mar. 16-Mar. 31) to ensure that our foot-traffic data reflect commercial activity as opposed to visits related to the closing down of a business. We find exact matches for 268 small businesses, mostly for streetfacing businesses. (Service companies without storefronts, such as construction, 
FIGURE 4

Impact of Shelter-in-Place Order on Select Alameda County Businesses

Figure 4 illustrates the mean change in foot traffic for Alameda County businesses relative to foot traffic for a business on Jan. 8, 2020. Foot-traffic data are from SafeGraph and reflect observed daily visits to a SafeGraph point of interest (POI) located within Alameda County. Because of variation in daily foot-traffic visits, visits per location are measured as the moving average over the preceding 7-day period. The industries depicted are chosen not to be comprehensive but as illustrative.

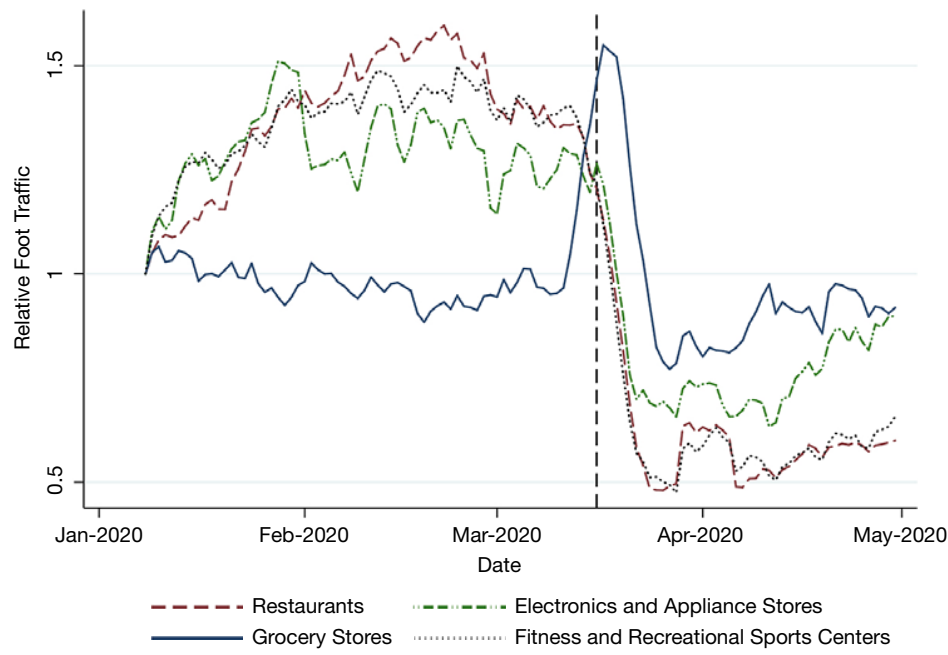

consulting, realty, and so forth, are often not covered in SafeGraph, nor would foot traffic represent a meaningful concept of commerce for these businesses.)

In Panel B of Table 3, we report summary statistics for our primary metric of interest, average daily foot traffic, for each location by coded industry. As in Figure 4, the reported figures account for variation in the number of observed devices by scaling the daily visits to an observed POI by the number of devices observed by SafeGraph in Alameda County per 100,000 residents. Data represent the overall mean number of standardized daily visits between Jan. 1, 2020, and Mar. 15, 2020. Across industries, this standardized measure of daily visits ranged from a mean (median) of 0.85 (0.74) for medical offices to 7.55 (5.37) for restaurants.

\section{Results}

We test whether the facets of small-business survival (revenue resiliency, labor flexibility, and committed cost) vary by ex ante firm size during the economic crisis caused by the COVID-19 shelter-in-place order. In our estimations, we consider the role of firm size using 2 independent variables: the natural logarithm of the precrisis count of workers (where "workers" equals employees +1 , the owner) and an indicator for a precrisis nonemployer firm. The nonemployer indicator is used to pick up any unique attributes of nonemployers that a continuous variable might miss. We then group predictions into 3 size buckets (following our caterer, taqueria, and pizza restaurant examples) to depict the patterns of the predicted effects by size type, always absorbing industry or firm fixed effects, to capture patterns orthogonal to these systematic influences. 


\section{A. Revenue-Resiliency Results}

\section{Oakland Survey Revenue-Resiliency Results}

Table 4 presents results from 2 revenue-resiliency analyses. In columns 1-4, we report estimates within the Oakland survey data as follows, denoting the small business by $i$ :

$$
\begin{aligned}
& \log (\% \triangle \text { RECEIPTS_DECLINE_MARCH })_{\mathrm{i}} \\
&=\beta_{0}+\beta_{1} \text { LOG_WORKERS }_{i}^{\text {Pre }}+\beta_{2} \text { NONEMPLOYER }_{i} \\
&+\beta_{3} \log (\% \triangle \text { RECEIPTS_DECLINE_FEB })_{\mathrm{i}} \\
&+\mu_{\text {MAIN_STREET }}+\mu_{\text {ESSENTIAL }}+\mu_{\text {INDUSTRY }}+\varepsilon_{i} .
\end{aligned}
$$

The dependent variable is the log of 1 plus the percentage-change decline in YoY gross receipts for Mar. 2020. ${ }^{9}$ The dependent variable is increasing in the decline in revenues. All columns include the variable $\log (\% \Delta$ RECEIPTS DECLINE_FEB), which is the same variable as the dependent variable except YoY revenue is reported as of Feb. 2020, thus allowing us to parse out the precrisis situation of the firm and focus on the effect of the pandemic stress. In addition, all columns include indicators for the business being located on Main Street $\left(\mu_{\text {MAIN_STREET }}\right)$ and whether or not the business is essential $\left(\mu_{\text {ESSENTIAL }}\right)$. All columns have our main independent variable, precrisis log of workers. Columns 2 and 4 also include the nonemployer indicator to allow for any unique attributes of this type of business. Columns 3 and 4 include industry fixed effects ( $\left.\mu_{\text {INDUSTRY }}\right)$.

Turning to the results, we first look to the conditioning variable $\log (\% \Delta$ RECEIPTS_DECLINE_FEB $)$. The March decline in receipts has a very tightly estimated elasticity of 0.220 to the February decline in receipts. This elasticity is well below 1, reflecting the large change in the setting in March. Nevertheless, this variable is the most important in terms of partial $R^{2}$ in the estimation, even much more so than the industry effects, which are surprisingly insignificant with other variables included. The variables reflecting Main Street and essential business (which sometimes compete with the industry effect for power) are also weak in explanatory power. In short, it appears that the shelter-in-place order affected businesses across the board, hitting those already in decline $22 \%$ more but with much idiosyncratic impact.

Our main variables of interest, LOG_WORKERS ${ }_{i}^{\text {Pre }}$ and precrisis NONEMPLOYER $_{i}$, are also statistically important. We find a gross-receipts elasticity of 0.027 to the number of precrisis workers in the firm once we allow nonemployer firms to exhibit their own pattern (columns 2 and 4). Larger firms and, to a lesser degree, nonemployers exhibit a greater percentage-revenue decline.

In Graph A of Figure 5, we plot the marginal effect of the log of workers and nonemployer status on the percentage decline in gross receipts for March at the mean value of all other variables (using the specification shown in column 4).

\footnotetext{
${ }^{9}$ Note that the variables for gross-receipt decline are reported in the survey in buckets, as depicted in Table 1, not as a continuous variable. We make a continuous variable by taking the midpoint of the bucket as the value. An ordinal logit estimation fits a similar pattern as what we report but with more noise.
} 
TABLE 4

Revenue Resiliency

\begin{abstract}
Table 4 presents 2 sets of revenue resiliency results for the City of Oakland. Columns 1-4 report OLS estimations from the City of Oakland COVID-19 small-business survey. The dependent variable is the reported revenue percentage-change decline, calculated as the natural logarithm of $1+$ percentage-change decline reported year over year (YoY) for Mar. 2020. We control for the same variable for February to focus on the March crisis impact. The main independent variables are the (preperiod) log of workers (employees +1 ) and a nonemployer indicator, per the Oakland survey data. The employee survey question asks the business for these worker counts as of before Mar. 2020. In columns 1 and 2, we include an indicator for the business being street-facing ("Main Street") and one for essential businesses, both from manual coding. Columns 3 and 4 add in industry fixed effects. Robust standard errors in columns 1-4 are in parentheses. Columns 5 and 6 report difference-in-differences estimates of the foot traffic for the same businesses in Oakland that could be matched to a SafeGraph point of interest (POI), including firm and day fixed effects. We limit to the Oakland survey sample to be able to include the precrisis log worker information. Standard errors in columns 5 and 6 are clustered by firm (in parentheses). ${ }^{*}$, ${ }^{\star *}$, and ${ }^{* \star *}$ indicate statistical significance at the $10 \%, 5 \%$, and $1 \%$ levels, respectively.
\end{abstract}

Dependent Variable

\begin{tabular}{|c|c|c|c|c|c|c|}
\hline & & & Dependen & Variable & & \\
\hline & $\log (\%$ & $\triangle$ RECEIPTS & DECLINE_N & $\mathrm{ARCH})$ & $\log (\mathrm{FOOT}$ & TRAFFIC) \\
\hline & 1 & 2 & 3 & 4 & 5 & 6 \\
\hline LOG_WORKERS (precrisis) & $\begin{array}{c}0.0126^{\star \star} \\
(0.00616)\end{array}$ & $\begin{array}{c}0.0274^{\star \star \star} \\
(0.00895)\end{array}$ & $\begin{array}{c}0.0099 \\
(0.0071)\end{array}$ & $\begin{array}{l}0.0271^{* * *} \\
(0.0103)\end{array}$ & & \\
\hline NONEMPLOYER & & $\begin{array}{l}0.0538^{\star \star} \\
(0.0246)\end{array}$ & & $\begin{array}{l}0.0593^{* *} \\
(0.0261)\end{array}$ & & \\
\hline POST $\times$ LOG_WORKERS (precrisis) & & & & & $\begin{array}{c}-0.0673 \\
(0.0435)\end{array}$ & $\begin{array}{r}-0.126^{\star *} \\
(0.0543)\end{array}$ \\
\hline POST × NONEMPLOYER & & & & & & $\begin{array}{r}-0.334^{*} \\
(0.192)\end{array}$ \\
\hline $\log (\% \triangle$ RECEIPTS_DECLINE_FEB $)$ & $\begin{array}{c}0.217^{\star \star \star} \\
(0.0402)\end{array}$ & $\begin{array}{c}0.225^{\star \star *} \\
(0.0403)\end{array}$ & $\begin{array}{c}0.219^{\star \star \star} \\
(0.0408)\end{array}$ & $\begin{array}{c}0.231^{\star \star \star} \\
(0.0412)\end{array}$ & & \\
\hline MAIN_STREET & $\begin{array}{r}0.0299^{\star} \\
(0.0166)\end{array}$ & $\begin{array}{c}0.0274 \\
(0.0167)\end{array}$ & $\begin{array}{c}0.0544 \\
(0.0799)\end{array}$ & $\begin{array}{c}0.0651 \\
(0.0732)\end{array}$ & & \\
\hline ESSENTIAL & $\begin{array}{l}-0.0107 \\
(0.0207)\end{array}$ & $\begin{array}{c}-0.00738 \\
(0.0201)\end{array}$ & $\begin{array}{l}0.00233 \\
(0.0265)\end{array}$ & $\begin{array}{r}0.00327 \\
(0.0266)\end{array}$ & & \\
\hline BUSINESS_SERVICES & & & $\begin{array}{r}-0.0673 \\
(0.0889)\end{array}$ & $\begin{array}{c}-0.0842 \\
(0.0835)\end{array}$ & & \\
\hline $\begin{array}{l}\text { CONSTRUCTION/ } \\
\text { MANUFACTURING/NENUE }\end{array}$ & & & $\begin{array}{c}0.0059 \\
(0.0326)\end{array}$ & $\begin{array}{c}-0.00359 \\
(0.0336)\end{array}$ & & \\
\hline FITNESS/GYM/NELLNESS & & & $\begin{array}{c}-0.0148 \\
(0.0868)\end{array}$ & $\begin{array}{c}-0.0302 \\
(0.0812)\end{array}$ & & \\
\hline MEDICAL_OFFICES & & & $\begin{array}{r}-0.00796 \\
(0.0986)\end{array}$ & $\begin{array}{c}-0.0187 \\
(0.0923)\end{array}$ & & \\
\hline PERSONAL_SERVICES_HOME & & & $\begin{array}{r}-0.0495 \\
(0.0473)\end{array}$ & $\begin{array}{c}-0.0728 \\
(0.0499)\end{array}$ & & \\
\hline PERSONAL_SERVICES_SHOP & & & $\begin{array}{c}-0.0641 \\
(0.0924)\end{array}$ & $\begin{array}{c}-0.0805 \\
(0.0865)\end{array}$ & & \\
\hline RESTAURANT & & & $\begin{array}{l}-0.0118 \\
(0.0851)\end{array}$ & $\begin{array}{l}-0.0367 \\
(0.0798)\end{array}$ & & \\
\hline RETAIL & & & $\begin{array}{c}-0.0348 \\
(0.0823)\end{array}$ & $\begin{array}{c}-0.0477 \\
(0.0763)\end{array}$ & & \\
\hline SALON & & & $\begin{array}{l}-0.0162 \\
(0.0847)\end{array}$ & $\begin{array}{l}-0.0387 \\
(0.0794)\end{array}$ & & \\
\hline Firm fixed effects & & & & & Yes & Yes \\
\hline Day fixed effects & & & & & Yes & Yes \\
\hline No. of obs. & 349 & 349 & 349 & 349 & 23,292 & 23,292 \\
\hline$R^{2}$ & 0.107 & 0.120 & 0.125 & 0.139 & 0.796 & 0.797 \\
\hline
\end{tabular}

We scatter-plot this margin using buckets of 5 workers for purposes of calculating the standard error, but note that because we are plotting the marginal effects by these size-based buckets, the confidence intervals are naturally larger than is the precision in the table reflecting the estimated slope, which is significant at the $1 \%$ confidence level. Having said that, interpreting the economic magnitude is important. We infer that the difference in revenue resiliency across firm size is significant but small relative to the overall revenue decline across the board. 


\section{FIGURE 5}

\section{Revenue Resiliency by Small-Business Type}

Graph A of Figure 5 plots the marginal effect of the precrisis number of workers on the Oakland survey decline in year-overyear (YoY) revenue as of Mar. 2020, taking all other covariates at the mean, based on the model in column 4 of Table 4 . The marginal effect is calculated by buckets of 5 employees, thus creating larger standard errors than in the continuous single statistic in the table. The sample in Graph B is Oakland businesses matched to SafeGraph points of interest (POIs). Plotted is the predicted natural logarithm of foot traffic over time by small-business type resulting from the difference-in-difference estimate of column 6 of Table 4, including firm and time fixed effects.
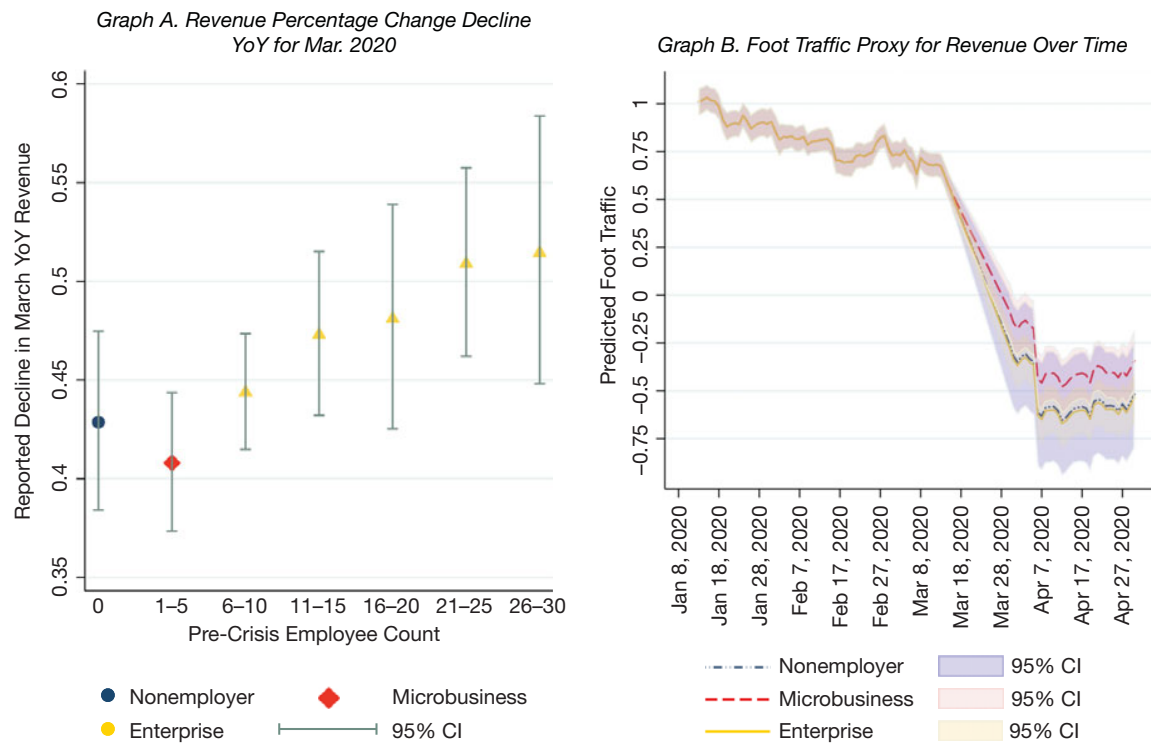

Despite considering the marginal effect differences small, the figure suggests meaningful differences in terms of our 3 small-business types, nonemployers, microbusiness, and enterprises. Averaged in their range, microbusinesses face a YoY revenue percentage decline for March of -0.408 , a large number but better than enterprises, which face a revenue decline of -0.476 as a percentage of the prior year's gross receipts. Interpreting the result in the context of our setup, microbusinesses seem to be endowed with the ability to ward off $14 \%$ of the shock relative to enterprises. In the context of real-world events captured by our hypothetical businesses, the taqueria, because it is small, is able to more nimbly keep a larger proportion of precrisis revenues.

Offering proof of the mechanism is beyond our data capacity and scope here, but we offer a few possibilities for future research consideration. First, our intuition in talking with many people and business owners over the course of this research is that nonemployers survive the crisis by managing their personal savings and opportunities for government support. For these business owners, pivoting operations can involve costs out of wealth and can be difficult, given the lack of employees who can develop and implement ideas. Microbusinesses, in contrast, have the incentive and employees to implement pivots. Another hypothesis is the possibility that loyalty to a business owner is higher in microbusinesses than in larger enterprises (in some cases, perhaps because the owner and 
employees are related by family.) As a result, worker participation in saving the business may be higher. Casting these hypotheses in our restaurant examples, it may be that the few workers at the taqueria are all core employees and are able to think and act upon creativity with the holistic company in mind. Larger enterprises may have more specialized workers (e.g., waitstaff) who potentially would not have such vision or loyalty. Again, we want to emphasize the caveat that we do not have the data to prove these assertions and offer them only to guide future research in this area.

\section{SafeGraph Revenue-Resiliency Results}

In the last 2 columns of Table 4, we turn to the SafeGraph data of foot traffic as a revenue proxy, again focusing on Oakland, where we know employee counts. These data are a panel, allowing us to estimate a model to absorb firm heterogeneity and time, akin to a difference-in-differences model but against the continuous variable LOG_WORKERS ${ }_{i}^{\text {Pre }}$ :

$$
\begin{aligned}
\log \left(\text { FOOT_TRAFFIC }_{i t}\right)= & \beta_{1} \text { LOG_WORKERS }_{i}^{\text {Pre }} \times \text { POST }_{t} \\
& +\beta_{2} \text { NONEMPLOYER }_{i} \times \operatorname{POST}_{t}+\gamma_{i}+\delta_{t}+\varepsilon_{i t} .
\end{aligned}
$$

The variables $\gamma_{i}$ and $\delta_{t}$ denote firm and day fixed effects, respectively. $\mathrm{POST}_{t}$ represents Mar. 30-Apr. 30, 2020.

As shown in column 6 of Table 4, foot traffic fell dramatically across firms during the POST period and was especially pronounced for nonemployers and larger businesses. We again turn to a graphical representation to put our economic magnitudes into perspective.

Graph B of Figure 5 plots the predicted $\log$ of FOOT_TRAFFIC ${ }_{i t}$ over time by small-business type, after removing firm fixed effects. Note that for the precrisis period, the lines pick up a single time-varying pattern because LOG_ WORKERS $_{i}^{\text {Pre }}$ is static by firm (and thus absorbed by the fixed effect) until Mar. 30, when the interaction with $\mathrm{POST}_{t}$ estimates elasticities by firm size. As the picture illustrates, all types of businesses incur a tremendous reduction in foot traffic after the shelter-in-place order; the average decline by Apr. 30, 2020, is $77.1 \%$. However, whereas enterprises and nonemployers face $78.7 \%$ and $78.3 \%$ declines in their foot traffic relative to Jan. 13, 2020, microbusinesses have somewhat higher revenue resiliency, facing only a $74 \%$ decline. This is not to say that a $74 \%$ decline in revenues is benign, but microbusinesses seem to be able to ward off $6 \%$ of the shock relative to the other types of business, on the order ( $14 \%$ better) of our finding in the Oakland survey. Although the difference-in-differences specification has desirable econometric properties, we draw our inference with caution, being subject to parallel-trend concerns even within industry.

\section{B. Labor-Flexibility Results}

In the forthcoming estimations of labor flexibility and committed costs, we need to control for revenue losses to avoid double-counting any effects we estimate in Table 4 by firm size. Thus, we create a revenue-loss index variable (REV_LOSS_INDEX), defined as the average of a standardized version of the percentage decline in revenue for March from the Oakland survey and a 
standardized version of the percentage change in foot traffic after the shelter-inplace order (defined to be April) relative to the preperiod foot traffic of Jan. 13-Feb. 18,2020 . Because some observations lack one or the other variable, we allow solo contributions of these standardized variables, thus expanding the sample size relative to using only a respondent's self-reported revenue decline or using only observed foot traffic.

\section{Oakland Survey Labor-Flexibility Results}

We now test whether the labor-flexibility facet of small-business survival varies by firm size in its reaction to the economic crisis caused by the pandemic. Table 5 presents estimates of labor flexibility in the Oakland survey in the following specification:

(6) Fractional logit $\left(\% \triangle\right.$ DECLINE_WORKERS $\left._{i}\right)=\beta_{1}$ LOG_WORKERS $_{i}^{\text {Pre }}$ $+\beta_{2}$ REV_LOSS_INDEX ${ }_{i}+\beta_{3}$ LOG_WORKERS $_{i}^{\text {Pre }} \times$ REV_LOSS_INDEX $_{i}$

$+\mu_{\text {MAIN_STREET }}+\mu_{\text {ESSENTIAL }}+\mu_{\text {INDUSTRY }}+\varepsilon_{i}$.

The dependent variable is a percentage-change decline of workers (full-time in columns 1-3 and part-time in columns 4-6). The main independent variable is LOG_WORKERS $_{i}^{\text {Pre }}$. Because the distribution of percentage-change decline ranges from 0 to 1, we estimate a fractional logit for efficiency. As before, we control for the Main Street and essential business effects and absorb industry effects. We include the revenue-loss index to control for the effects documented in Table 4. We also interact the revenue-loss index with LOG_WORKERS ${ }_{i}^{\text {Pre }}$ in some specifications to test whether firm size alters the relationship between labor flexibility and revenues. We focus our analysis on microbusinesses and small enterprises because nonemployers have no employees.

As Table 5 reports, we find that layoffs of full-time workers (columns 1-3) exhibit an elasticity to firm size of 0.127 , controlling for industry effects (column 2), and layoffs of part-time workers (columns 4-6) exhibit an elasticity of 0.172 (column 5) to firm size with these controls. A second result in Table 5 is that although the relationship between revenue losses and labor layoffs is high, as one would expect, the interaction of revenue loss and precrisis level of workers does not add explanatory power. Thus, labor flexibility does not appear to be mediated through differentials in revenue losses among enterprises relative to microbusinesses.

As before, we turn to a figure to depict the economic meaning of our results. Graph A of Figure 6 plots the relationship between the marginal effect of LOG_WORKERS $S_{i}^{\text {Pre }}$ on layoffs, taking all other variables at the mean value. In contrast to our revenue-resiliency results, the magnitude differences for our labor-flexibility results reflect a large difference of outcomes. We again interpret over the entire range of microbusinesses and enterprises to understand the importance of labor flexibility by stable Main Street firms versus growthoriented firms. For full-time workers, enterprises (the triangles in the scatter plots) on average laid off $38.1 \%$ of workers, whereas microbusinesses (the diamonds) laid off only $17.7 \%$. For part-time workers, enterprises laid off 
TABLE 5

Labor Flexibility: Oakland Survey

\begin{tabular}{|c|c|c|c|c|c|c|}
\hline \multirow{2}{*}{$\begin{array}{l}\text { The estimates in Table } 5 \text { are } \\
\text { sample is small businesses in } \\
\text { precrisis log of workers (emp } \\
\text { because of the lack of employe } \\
\text { laid off relative to the precrisis } \\
\text { being street-facing ("Main S } \\
\text { REV_LOSS_INDEX variable, } \\
\text { standardized percentage cha } \\
\text { workers. Columns } 2,3,5 \text {, and } \\
\text { statistical significance at the } 1 \\
\text { Model } \\
\text { Dependent Variable }\end{array}$} & \multicolumn{6}{|c|}{ Fractional Logit: Reporting Marginal Effect } \\
\hline & \multicolumn{3}{|c|}{$\begin{array}{l}\text { Percentage-Change Decline in } \\
\text { Full-Time Workers }\end{array}$} & \multicolumn{3}{|c|}{$\begin{array}{l}\text { Percentage-Change Decline in } \\
\text { Part-Time Workers }\end{array}$} \\
\hline & 1 & 2 & 3 & 4 & 5 & 6 \\
\hline LOG_WORKERS (precrisis) & $\begin{array}{c}0.117^{\star \star \star} \\
(0.0150)\end{array}$ & $\begin{array}{c}0.127^{\star \star \star} \\
(0.0168)\end{array}$ & $\begin{array}{c}0.128^{\star \star \star} \\
(0.0167)\end{array}$ & $\begin{array}{c}0.165^{\star \star \star} \\
(0.0207)\end{array}$ & $\begin{array}{c}0.172^{\star \star \star} \\
(0.0238)\end{array}$ & $\begin{array}{c}0.173^{\star \star \star} \\
(0.0237)\end{array}$ \\
\hline REV_LOSS_INDEX & $\begin{array}{l}0.0769^{\star \star \star} \\
(0.0200)\end{array}$ & $\begin{array}{l}0.0692^{\star \star \star} \\
(0.0193)\end{array}$ & $\begin{array}{r}0.0844^{*} \\
(0.0452)\end{array}$ & $\begin{array}{l}0.0680^{\star \star \star} \\
(0.0239)\end{array}$ & $\begin{array}{l}0.0696^{\star \star *} \\
(0.0243)\end{array}$ & $\begin{array}{l}0.117^{\star} \\
(0.0685)\end{array}$ \\
\hline $\begin{array}{l}\text { LOG_WORKERS (precrisis) } \times \\
\text { REV_LOSS_INDEX }\end{array}$ & & & $\begin{array}{c}-0.00749 \\
(0.0196)\end{array}$ & & & $\begin{array}{c}-0.0214 \\
(0.0306)\end{array}$ \\
\hline MAIN_STREET & $\begin{array}{l}0.0718^{\star \star} \\
(0.0360)\end{array}$ & $\begin{array}{c}-0.0238 \\
(0.174)\end{array}$ & $\begin{array}{c}-0.0275 \\
(0.175)\end{array}$ & $\begin{array}{l}0.0435 \\
(0.0484)\end{array}$ & $\begin{array}{c}-0.0893 \\
(0.244)\end{array}$ & $\begin{array}{c}-0.104 \\
(0.243)\end{array}$ \\
\hline ESSENTIAL & $\begin{array}{r}-0.0842^{*} \\
(0.0443)\end{array}$ & $\begin{array}{l}-0.0636 \\
(0.0604)\end{array}$ & $\begin{array}{c}-0.0651 \\
(0.0613)\end{array}$ & $\begin{array}{r}-0.137^{\star \star} \\
(0.0581)\end{array}$ & $\begin{array}{r}-0.184^{\star *} \\
(0.0714)\end{array}$ & $\begin{array}{l}-0.189^{\text {*** }} \\
(0.0727)\end{array}$ \\
\hline BUSINESS_SERVICES & & $\begin{array}{c}0.0105 \\
(0.174)\end{array}$ & $\begin{array}{r}0.0141 \\
(0.174)\end{array}$ & & $\begin{array}{c}0.159 \\
(0.254)\end{array}$ & $\begin{array}{c}0.176 \\
(0.252)\end{array}$ \\
\hline $\begin{array}{l}\text { CONSTRUCTION/ } \\
\text { MANUFACTURING NENUE }\end{array}$ & & $\begin{array}{l}-0.017 \\
(0.0611)\end{array}$ & $\begin{array}{l}-0.0165 \\
(0.0609)\end{array}$ & & $\begin{array}{c}-0.00468 \\
(0.0841)\end{array}$ & $\begin{array}{r}-0.00233 \\
(0.0828)\end{array}$ \\
\hline FITNESS/GYM/NELLNESS & & $\begin{array}{r}0.0791 \\
(0.182)\end{array}$ & $\begin{array}{c}0.0819 \\
(0.181)\end{array}$ & & $\begin{array}{c}0.0436 \\
(0.240)\end{array}$ & $\begin{array}{c}0.0554 \\
(0.237)\end{array}$ \\
\hline MEDICAL_OFFICES & & $\begin{array}{c}0.0236 \\
(0.211)\end{array}$ & $\begin{array}{c}0.0288 \\
(0.213)\end{array}$ & & $\begin{array}{c}0.165 \\
(0.299)\end{array}$ & $\begin{array}{c}0.183 \\
(0.297)\end{array}$ \\
\hline PERSONAL_SERVICES_HOME & & $\begin{array}{c}-0.0374 \\
(0.112)\end{array}$ & $\begin{array}{c}-0.0375 \\
(0.112)\end{array}$ & & $\begin{array}{c}-0.0837 \\
(0.129)\end{array}$ & $\begin{array}{c}-0.0844 \\
(0.127)\end{array}$ \\
\hline PERSONAL_SERVICES_SHOP & & $\begin{array}{c}0.0859 \\
(0.186)\end{array}$ & $\begin{array}{r}0.0904 \\
(0.187)\end{array}$ & & $\begin{array}{c}0.176 \\
(0.254)\end{array}$ & $\begin{array}{c}0.194 \\
(0.252)\end{array}$ \\
\hline RESTAURANT & & $\begin{array}{c}0.053 \\
(0.172)\end{array}$ & $\begin{array}{r}0.0567 \\
(0.172)\end{array}$ & & $\begin{array}{c}0.0898 \\
(0.240)\end{array}$ & $\begin{array}{c}0.105 \\
(0.236)\end{array}$ \\
\hline RETAIL & & $\begin{array}{c}0.0783 \\
(0.168)\end{array}$ & $\begin{array}{c}0.0827 \\
(0.169)\end{array}$ & & $\begin{array}{l}0.191 \\
(0.233)\end{array}$ & $\begin{array}{c}0.209 \\
(0.230)\end{array}$ \\
\hline SALON & & $\begin{array}{c}0.286 \\
(0.194)\end{array}$ & $\begin{array}{c}0.288 \\
(0.192)\end{array}$ & & $\begin{array}{c}0.102 \\
(0.246)\end{array}$ & $\begin{array}{c}0.118 \\
(0.243)\end{array}$ \\
\hline $\begin{array}{l}\text { No. of obs. } \\
R^{2}\end{array}$ & $\begin{array}{r}556 \\
0.099\end{array}$ & $\begin{array}{r}556 \\
0.117\end{array}$ & $\begin{array}{r}556 \\
0.118\end{array}$ & $\begin{array}{r}442 \\
0.096\end{array}$ & $\begin{array}{r}442 \\
0.103\end{array}$ & $\begin{array}{r}442 \\
0.104\end{array}$ \\
\hline
\end{tabular}

$49.6 \%$ of workers and microbusinesses only $23.8 \%$. Recalling that the ability to lay off employees to downsize costs can represent a positive aspect for survival (while acknowledging that such language is not indicative of worker welfare), this result implies that microbusinesses face a much larger risk of not surviving on this metric. In particular, microbusinesses exhibit roughly half the labor flexibility of enterprises based on these averages.

As before, we cannot prove mechanisms for these results. However, here, the intuition is fairly straightforward. In our story frame, the taqueria has core employees who are necessary to keep the business open. The pizzeria, on the other 


\section{FIGURE 6}

\section{Labor Flexibility by Small-Business Type}

The sample in Graph A is the small businesses in Oakland covered by the City of Oakland COVID-19 small-business survey. Plotted is the predicted decline in employees by small-business type resulting from columns 2 and 5 of Table 5 . The sample for Graphs B, C, and D is from HomeBase. Graph B plots the predicted change in workers for the Oakland area (zip code 94XXX) small businesses covered by HomeBase using the model from column 3 of Table 6 . Graph $\mathrm{C}$ plots the predicted change in workers for all U.S. small businesses covered by HomeBase using the model from column 6 of Table 6, and Graph D plots the predicted change in wages for all U.S. small businesses covered by HomeBase using the model from column 9 of Table 6 . In Graphs B, C, and D, the $y$-scale has been normalized to reflect changes in employment and wages for microbusinesses and enterprises relative to Jan. 5,2020 , and predicted log-differences have been converted to percentage changes in workers/ wages.

Graph A. Decline in Workers - Oakland Survey

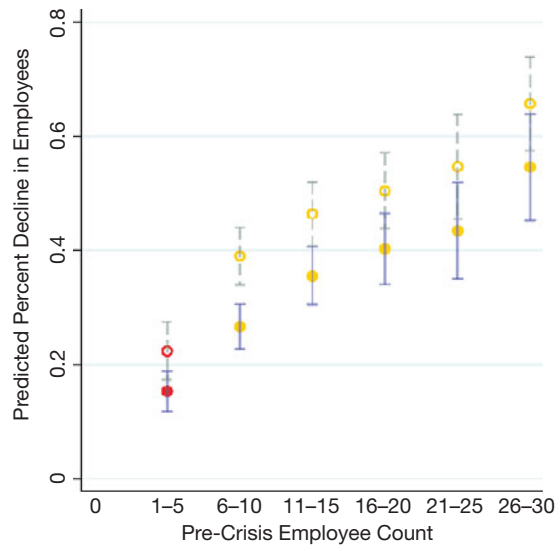

- Microbusiness (FT) $\quad$ Microbusiness (PT)

- Enterprise (FT)

$95 \% \mathrm{Cl}(\mathrm{FT})$

Graph C. Small Business Workers - Homebase National

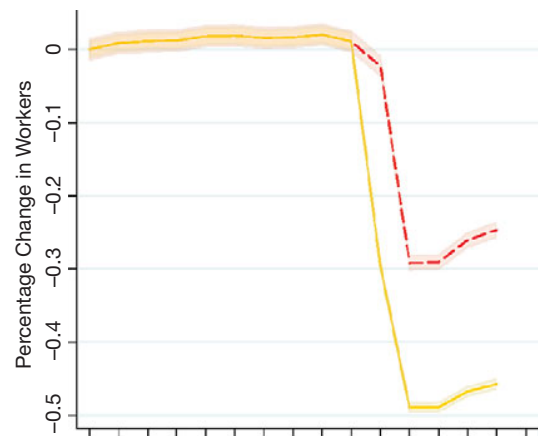

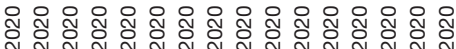

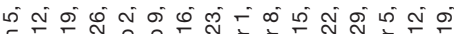

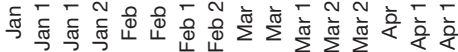

$\begin{array}{ll}\text { Microbusiness } & \text { Enterprise } \\ 95 \% \mathrm{Cl} & 95 \% \mathrm{Cl} \\ \text { Microbusiness } & \text { Enterprise }\end{array}$

Graph B. Small Business Workers - HomeBase Data: Oakland Area

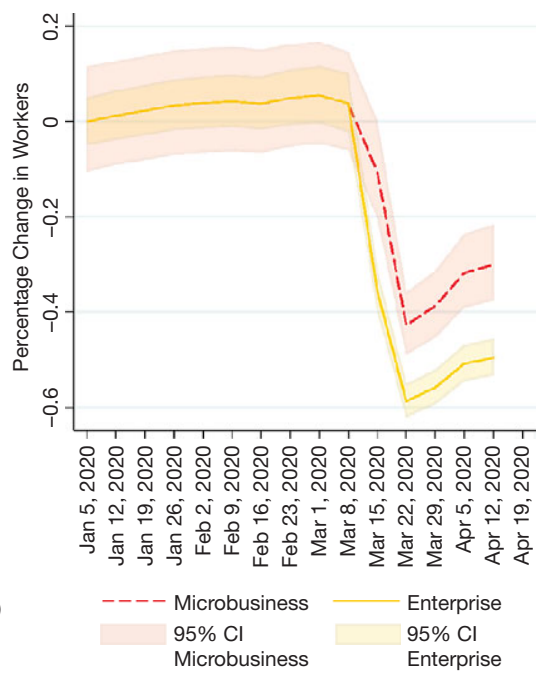

Graph D: Small Business Payroll - HomeBase National

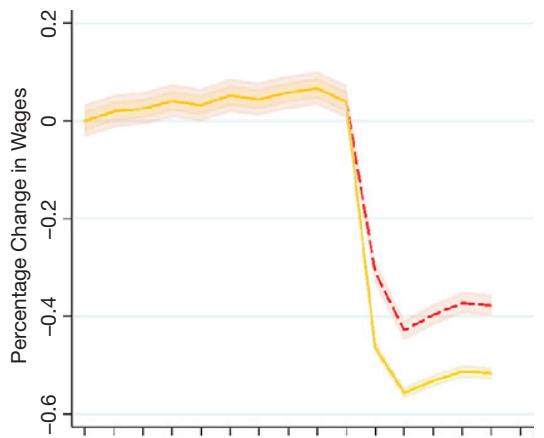

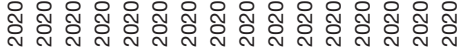

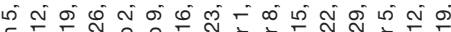

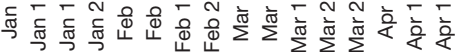

\begin{tabular}{cl}
$-1---$ Microbusiness & Enterprise \\
\hline $95 \% \mathrm{Cl}$ & $95 \% \mathrm{Cl}$ \\
Microbusiness & Enterprise
\end{tabular}


hand, has the flexibility to downsize noncore employees when demand collapses for its goods and services.

\section{HomeBase Labor-Flexibility Results}

Parallel with the Oakland survey data, we now look at the employment and payroll data from HomeBase. As before, we combine with a revenue-loss data set, in this case, with foot-traffic data from SafeGraph. Establishments in the HomeBase data are anonymized; therefore, we cannot match firm to firm. Instead, we match each HomeBase establishment based on its industry and zip code to SafeGraph foot-traffic data and use the mean weekly foot traffic for SafeGraph POIs within the same industry and zip code as a proxy for revenues. For our measure of firm size, we use a HomeBase establishment's average headcount data between Jan. 1, 2020, and Feb. 15, 2020. We focus our labor-flexibility estimations by excluding nonemployers.

Denoting index $j$ to indicate the industry and zip code of firm $i$, we estimate parameters from the following:

$$
\begin{aligned}
& \text { LOG_LABOR }_{i t}=\beta_{1} \text { LOG_FOOT_TRAFIC }_{j t}+\beta_{2} \text { LOG_FOOT_TRAFFIC }_{j t} \\
& \times \text { POST }_{t}+\beta_{3} \text { LOG_WORKERS }_{i}^{\text {Pre }} \times \text { POST }_{t}+\beta_{4} \text { LOG_WORKERS }_{i}^{\text {Pre }} \\
& \times \text { LOG_FOOT_TRAFFIC }_{j t}+\beta_{5} \text { LOG_WORKERS }_{i}^{\text {Pre }} \\
& \times \text { LOG_FOOT_TRAFIC }_{j t} \times \text { POST }_{t}+\gamma_{i}+\delta_{t}+\varepsilon_{i t},
\end{aligned}
$$

where $L O G \_L A B O R \Delta_{i t}$ is either i) the $\log$ difference in weekly workers relative to the week of Jan. 5, 2020 (LOG_WORKERS $\left.\Delta_{i t}\right)$, or ii) the log difference in weekly wages relative to the week of Jan. 5, 2020 (LOG_PAYROLL $\left.\Delta_{i t}\right)$. The variables $\gamma_{i}$ and $\delta_{t}$ denote firm and week fixed effects, respectively. POST ${ }_{t}$ represents the weeks commencing Mar. 15-Apr. 12, 2020. Results are presented in Table 6, first for the area surrounding Oakland (the 94XXX zip codes, including the East Bay, North Bay, and San Francisco) in columns 1-3 and then nationally (in columns 4-9). The results are not sensitive to defining the Oakland area more narrowly, and we cluster standard errors at the firm level to balance the panel's influence. Columns 4-9 widen the sample nationally, and columns 7-9 consider payroll rather than worker counts, but we are more cautious in magnitude interpretation with regard to payroll because the sample size declines materially after the crisis relative to the employment numbers, suggesting a selection problem.

The specification is, as in the foot-traffic estimation, akin to a difference-indifferences approach, except that we are interested in the POST effect surrounding the continuous variable $\mathrm{LOG}_{-} \mathrm{WORKERS}_{i}^{\text {Pre }}$. Our main variable of interest, LOG_WORKERS $_{i}^{\text {Pre }} \times$ POST $_{t}$, estimates how a firm's reliance on labor flexibility during the crisis varies by firm size. We find that the small businesses with more precrisis workers experience larger decreases in workers and payroll, with a postperiod shock to the elasticity of labor to the firm size of approximately -0.22 to -0.28 (columns 2,5 , and 8 ). (We obtain almost identical estimates if we use the industry and zip code as our unit of observation.)

In columns 3, 6, and 9 of Table 6, we add the 3-way interaction of LOG_WORKERS $_{i}^{\text {Pre }} \times$ LOG_FOOT_TRAFIC $_{j t} \times$ POST $_{t}$ to examine whether 


\section{TABLE 6}

\section{Labor Flexibility: HomeBase Payroll Data}

The estimates in Table 6 are from a difference-in-differences specification. The sample is the set of firms in the national HomeBase data, matched to the industry and zip-code data in SafeGraph. In columns $1-3$, the sample is restricted to the firms in the Oakland area (zip codes 94XXX). Observations are a weekly panel from the week commencing Jan. 5, 2020, through the week commencing Apr. 12, 2020. The dependent variable in columns 1-6 is the log difference between the weekly workers in a week and workers for the week of Jan. 5 (LOG_WORKERSA), and in columns 7-9, it is the log difference between the payroll in a week and weekly payroll for the week of Jan. 5 (LOG_PAYROLL $\triangle$ ). The main independent variable is the precrisis log of workers (defined in HomeBase as the average from Jan. 1, 2020-Feb. 15, 2020) interacted with POST. Firm and week fixed effects are included. POST indicates weeks after Mar. 15, 2020. LOG FOOT TRAFFIC is from SafeGraph and is matched to HomeBase firms at the industry-zip code level. Nonemployer data are not included because of the lack of employees. Firm-clustered standard errors are in parentheses. ${ }^{*}$, ${ }^{* *}$, and ${ }^{* * *}$ indicate statistical significance at the $10 \%, 5 \%$, and $1 \%$ levels, respectively.

Dependent Variable

POST $\times$ LOG_WORKERS (precrisis)

LOG_FOOT_TRAFFIC

POST $\times$ LOG_FOOT_TRAFFIC

LOG_WORKERS (precrisis) × LOG_FOOT_TRAFFIC

POST $\times$ LOG_WORKERS (precrisis) $\times$ LOG_FOOT_TRAFFIC

Firm fixed effects

Day fixed effects

No. of obs.

No. of businesses

$R^{2}$
LOG_WORKERSA, National Sample

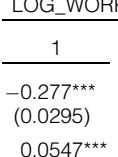

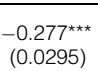

$$
\begin{array}{r}
-0.0114 \\
(0.0183)
\end{array}
$$

$$
\begin{gathered}
5 \\
\hline-0.278^{\star \star \star} \\
(0.00399) \\
0.0461^{\star \star \star} \\
(0.00191) \\
-0.00483^{\star \star} \\
(0.00196)
\end{gathered}
$$

$(0.0490)$

$0.0331^{*}$

0.0122

(0.0268)

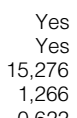

\begin{tabular}{|c|c|c|}
\hline 7 & 8 & 9 \\
\hline $\begin{array}{c}-0.220^{\star \star \star} \\
(0.00903)\end{array}$ & $\begin{array}{c}-0.220^{\star \star \star} \\
(0.00907)\end{array}$ & $\begin{array}{c}-0.198^{\star \star \star} \\
(0.0232)\end{array}$ \\
\hline \multirow[t]{4}{*}{$\begin{array}{c}0.0605^{\star * *} \\
(0.00421)\end{array}$} & $\begin{array}{c}0.0601^{\star \star \star} \\
(0.00432)\end{array}$ & $\begin{array}{c}-0.0179 \\
(0.0116)\end{array}$ \\
\hline & $\begin{array}{c}0.000732 \\
(0.00458)\end{array}$ & $\begin{array}{c}-0.0124 \\
(0.0135)\end{array}$ \\
\hline & & $\begin{array}{c}0.0389^{\star \star *} \\
(0.00575)\end{array}$ \\
\hline & & $\begin{array}{c}0.0063 \\
(0.00674)\end{array}$ \\
\hline Yes & Yes & Yes \\
\hline Yes & Yes & Yes \\
\hline 420,508 & 420,508 & 420,508 \\
\hline 34,447 & 34,447 & 34,447 \\
\hline & 0.594 & 0.594 \\
\hline
\end{tabular}

Yes

Yes
15,276
1,266

1,266
0.622
Yes

Yes

1,266
0.623

$\begin{array}{rr}\text { Yes } & \text { Yes } \\ \text { Yes } & \text { Yes } \\ 646,494 & 646,494 \\ 52,307 & 52,307 \\ 0,581 & 0,581\end{array}$

LOG_PAYROLLA, National Sample 
these effects are coming from shocks to the elasticity of labor to revenues varying by firm size or if the effect is just from labor-utilization adjustments by firm size that are independent of revenue resiliency. To make such an assessment, we first look at how the precrisis elasticity of labor costs to revenue vary by firm size. We find that the revenue-to-cost relationship is highly dependent on firm size, noting that the inclusion in columns 3, 6, and 9 of $\mathrm{LOG}_{-}$WORKERS ${ }_{i}^{\text {Pre }} \times$ LOG_FOOT_TRAFFIC $_{j t}$ erodes the relationship between $\mathrm{LOG}_{-} \mathrm{LABOR} \Delta_{i t}$ and LOG_FOOT_TRAFFIC $_{j t}$ alone. The interpretation, consistent with the role of a core employee in our example of a taqueria versus pizza restaurant, is that larger firms generally exhibit more labor scaling with revenue. Notably, however, the pandemic shock does not alter the relationship very much: The triple interaction of POST with firm size and revenues (foot traffic) is not significant in columns 3 and 9. It is positive and significant in column 6, the national sample of workers, suggesting that, if anything, the pandemic shock makes the elasticity of labor to the revenue macro shock even stronger for larger enterprises. This result, however, does not materially affect the statistical or economic significance of the coefficient on LOG_WORKERS ${ }_{i}{ }^{\text {Pre }} \operatorname{POST}_{t}$. This leads to the conclusion that the firm-size effect on employment is primarily the direct effect of the shock on labor, not one working through a change in the elasticity of labor cost to revenues that varies by size.

We turn to graphs to depict the economic magnitude. In particular, we use the estimations in columns 3,6, and 9 of Table 6 to depict changes in worker counts across microbusinesses and enterprises relative to the first week of our panel. Graph B of Figure 6 presents the column 3 marginal effects for the Oakland region. The parallel implications from Graph B, next to Graph A, are evident. The fall in employment is sharp and drastic. Yet microbusinesses experience a noticeably lower decline in workers relative to precrisis levels, indicating a lower flexibility in adjustments. When we translate these predictions to business type, we find that by the week of Apr. 12, 2002, workers decline by $49.6 \%$ for enterprises but only by $30.0 \%$ for microbusinesses in Oakland. These numbers are very close to our survey estimates in Graph A of Figure 6 (among part-time employees, 49.6\% decline for enterprises and $23.8 \%$ decline for microbusinesses).

Graph $\mathrm{C}$ of Figure 6 depicts the national results, with a very similar relationship as Graph B. Relative to the Oakland results, the decline in workers is slightly less on average; however, the difference between microbusinesses and enterprises remains evident. Whereas microbusinesses respond to the pandemic with a reduction in workers of $24.7 \%$ by the week of Apr. 12, enterprises on average reduced their workforce by $45.7 \%$.

Finally, Graph D of Figure 6 plots the predicted time pattern of payrolls for national establishments from the estimation in column 9 of Table 6, again removing firm effects. The payroll data are, as mentioned, less reliable in that there appears to be selection in reporting in the later month. Nevertheless, we find that the percentage decline is a large $46.5 \%$ on average, but the differential by firm size is a bit tighter. Whereas enterprises are able to cut back payrolls by $51.7 \%$, microbusinesses only are able to trim these costs by roughly two-thirds as much, $37.8 \%$. Thus, 
our punchline labor-flexibility result is that when facing a large macro shock, microbusinesses have only one-half to two-thirds as much labor flexibility as enterprises, again with the caveat that our estimation, even in this stringent difference-indifferences specification, could be subject to other time-series differences correlated with employment size within industry. Nevertheless, this finding has a direct implication for the PPP design, offering nuance to the assessment of Chetty et al. (2020), who find that the PPP failed to spur employment across all small businesses. We return to this topic in Section V.

\section{Committed Costs: Closure Risk}

Finally, we turn to committed costs. We cannot observe committed costs directly. Instead, we take guidance from our framework, which indicates that once we have removed the heterogeneities of revenue resiliency and labor flexibility, the residual must contain the role of committed costs in survival. We therefore use the variable CLOSURE_RISK as a proxy for committed costs, understanding that any inference we would find is the least well identified of our estimations.

In particular, within the Oakland survey, we estimate the following:

$$
\begin{aligned}
& \text { Ordered logit }(\text { CLOSURE_RISK } \\
& i)=\beta_{1} \text { LOG_WORKERS }_{i}^{\text {Pre }} \\
& \quad+\beta_{2} \text { REV_LOSS_INDEX }_{i}+\beta_{3} \% \triangle \text { DECLINE_WORKERS }_{i} \\
& \quad+\beta_{4} \text { DECLINING }_{i}+\sum_{k=1}^{\mathrm{K}} \xi_{\mathrm{k}} \text { INTERIM_OUTCOME }_{i k} \\
& \quad+\mu_{\text {MAIN_STREET }}+\mu_{\text {INDUSTRY }}+\varepsilon_{i} .
\end{aligned}
$$

CLOSURE_RISK ${ }_{i}$ is the ordered answer to the Oakland survey question of how concerned a business owner is about closure. We include the revenue-loss index and percentage-change decline in total workers to absorb those firm-level determinants of closure. We also include whether the firm was declining in the February YoY gross receipts. Finally, and perhaps most importantly, we include our interim outcome measures $\sum_{k=1}^{\mathrm{K}} \xi_{\mathrm{k}}$ INTERIM_OUTCOME $\mathrm{E}_{i k}$ that we handcollected. The idea is that we want to fully absorb business-level heterogeneities unrelated to the longer-term effects of committed (fixed) costs. Thus, our collection of the late-April (interim) outcome of the firm allows us to remove any additional variation related to variable costs that we do not observe perfectly in the survey data. We also include the MAIN_STREET and INDUSTRY variables for this purpose.

Once we have removed all of these causes of closure risk, we argue that any residual variation picked up by $\beta_{1}$ LOG_WORKERS $_{i}^{\text {Pre }}$ reflects the fact that committed costs vary (if any) by the size of the small business.

The results are presented in Table 7 . We find that committed costs (the residual component of closure risk unaccounted for by the covariates) is increasing in LOG_WORKERS $_{i}^{\text {Pre }}$, across the columns. The exception is column 2, where the inclusion of the nonemployer dummy causes a horse race for the upward trend. The covariates of REV_LOSS_INDEX ${ }_{i}$ and $\% \triangle$ DECLINE_WORKERS $_{i}$ also strongly predict closure risk. The other variables included to control for unobservable revenue 
TABLE 7

Committed Costs Results: Residual of Closure Risk

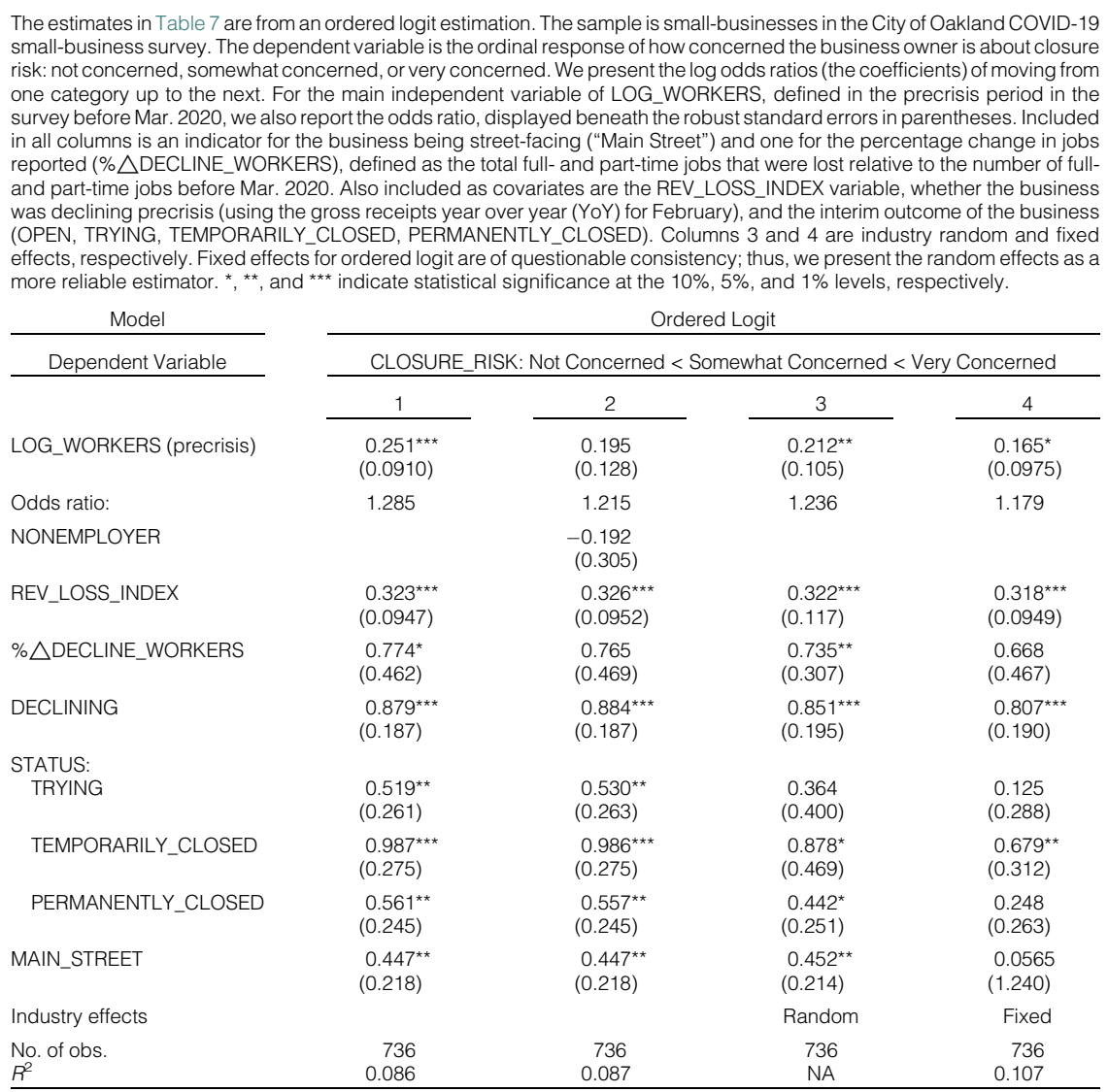

changes or variable costs (DECLINING and INTERIM_OUTCOME) are also important, in signs expected, in explaining expected closure. We include an industry-fixed-effects model (column 4) as well as a random-effects model (column 3). Fixed effects for ordered logit are of questionable consistency; thus, the random effects may be preferred as a more reliable estimator.

In an ordered logit, the coefficients are log odds ratios. We therefore exponentiate these coefficients in the line beneath the standard error to allow for an oddsratio interpretation of the effect of LOG_WORKERS ${ }_{i}^{\text {Pre }}$. Across respondents, a $10 \%$ increase in workers is associated with a $2 \%$ increase in the odds of being at a level higher in closure risk.

As previously, we present these estimated effects graphically to highlight the marginal effect by the small-business type. Figure 7 plots the marginal effect of worker size from column 4 of Table 7, taking all the other variables at the mean level. The picture focuses on the prediction of being in the highest-risk category, by the buckets of employees, as before. We find that closure risk overall is incredibly high, as we showed 


\section{FIGURE 7}

\section{Residual Closure Risk (Committed Costs) by Small-Business Type}

The sample in Figure 7 is small businesses in the City of Oakland COVID-19 small-business survey. Plotted is the predicted effect of firm size on self-reported closure risk, from the ordered logit estimation of column 4 of Table 7.

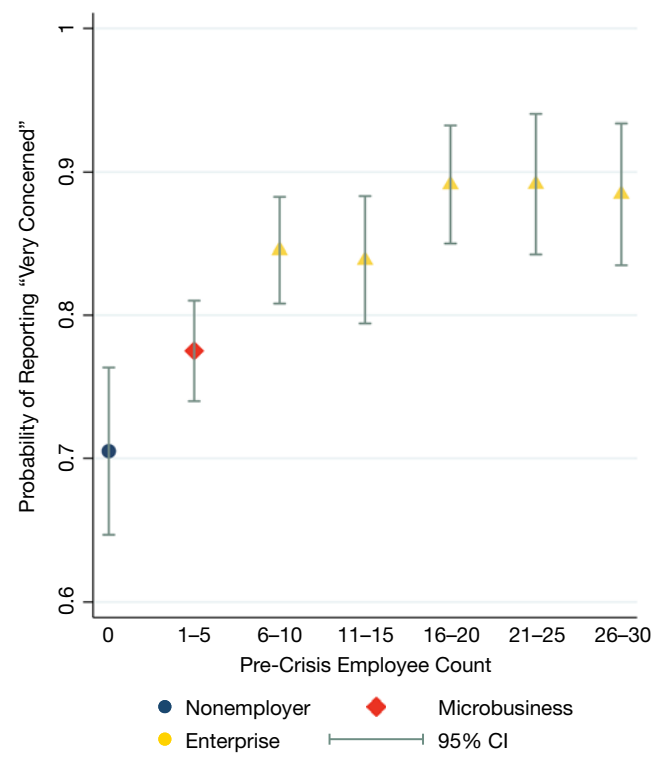

in the summary statistics, and that a clear relationship exists between firm size and closure risk beyond the effect of the covariates. In particular, in explaining residual closure risk, enterprises have an overall $11 \%$ greater outlook of "very concerned" compared with microbusinesses and a roughly $20 \%$ greater outlook of "very concerned" relative to nonemployers. We interpret these results as indicating that, relative to microbusinesses and nonemployers, enterprises face a respective $11 \%$ and $20 \%$ higher closure risk as a result of committed costs. We, of course, need the caveat that in drawing this inference, we are relying on a proxy for fixed costs, as guided by our framework in Section II. Nonetheless, the result is quite intuitive; a larger establishment faces a higher role of capital (and thus debt) and a higher role of property costs in its design. What is important is that the finding controls for the importance of revenue and labor, as well as interim variable costs we can measure with interim outcomes. Thus, we think our interpretation of committed costs is quite plausible.

\section{Policy Program Features}

With survival capabilities results in hand, we turn to an examination of how these survival capabilities are, or are not, compatible with small-business assistance programs across the classification of businesses we study. We use the following table to direct the discussion, where the top 3 rows summarize our findings regarding the primary survival capabilities, and the bottom rows examine how these capabilities relate to policy options. 
Survival Capability

Exhibit revenue resiliency

Exercise labor costs flexibility

Rely on low/flexible committed costs

Small-Business Assistance Program

Subsidized working capital loans

Labor-cost grants and subsidies

Lease or debt payment-restructuring subsidies

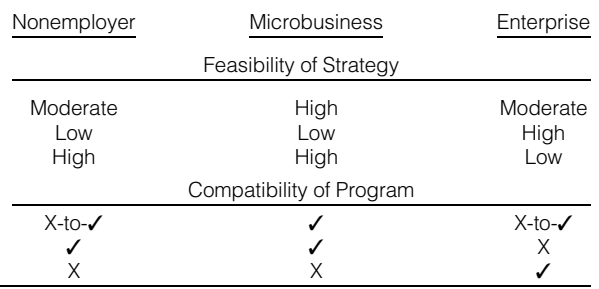

We start with microbusinesses. Microbusinesses have low labor flexibility because their employees must be jacks-of-all-trades. We find that their survival depends on maintaining revenues to cover these inflexible labor costs, as well as having relatively lower residual committed costs. Thus, working capital loan programs that focus on supporting revenue resiliency through financing activities such as restocking inventories and conducting repairs are highly compatible with microbusinesses' survival capabilities that depend on maintaining precrisis revenues. Recall, for instance, our hypothetical taqueria faced with a local economic crisis. Lacking the ability to lay off staff, the business owner was faced with the stark choice of demonstrating revenue resiliency or shutting down. Assistance to support these revenue strategies following an adverse economic shock is reflected in conventional Economic Injury Disaster Loans (EIDLs) offered through the SBA. According to the SBA, "[t] he sole purpose of an [EIDL] is to help a small business meet its working capital requirements during the disaster-affected period until normal operations resume." To this end, loan proceeds are calculated as a function of precrisis gross margins, and recipients are prohibited from using proceeds to refinance long-term debt or expand operations. Instead, loan proceeds are intended to aid small businesses in rebuilding revenues to precrisis levels. Programs such as the New York Forward Fund as well as the Main Street Lending Program are similarly designed to provide working capital to businesses seeking to rebuild revenues in connection with the COVID-19 pandemic.

Likewise, PPP-like programs are also well suited for microbusinesses. The taqueria cannot lay off the few jack-of-all-trades employees and still remain open, thus making microbusinesses an ideal target for the PPP, as well as for several other programs created by the CARES Act. For instance, the CARES Act provides for a refundable payroll tax credit for employers to offset the cost of maintaining employees. The role of the PPP (and similar programs) for microbusinesses contrasts our findings with those of Chetty et al. (2020), who evaluate the efficacy of the PPP in stimulating employment. Using a national sample of small businesses, these authors find that the PPP had no meaningful impact on employment rates, leading these authors to conclude that "providing liquidity itself may be inadequate to restore employment at small businesses." Critically, however, their sample of firms focused on enterprises; the smallest strata of firms they considered had an average of 45 employees. Yet, as we have shown, it is precisely these larger employer firms that are the most likely to rely on their labor flexibility to weather the COVID-19 pandemic, a survival tactic that is at odds with the PPP's labor subsidy. 
Turning to nonemployers, we find that these businesses exhibit neither revenue resiliency nor labor-cost flexibility. Instead, their survival relies on low committed costs (20\% lower than enterprises). These results are complemented by prior research showing nonemployers' personal flexibility in accepting nonpecuniary utility rather than full income in downturns (e.g., Moskowitz and VissingJørgensen (2002)). Because this personal utility nevertheless consumes personal wealth (which has limits), policies aimed at preserving incomes for self-employed individuals are well suited to support nonemployer owners through an economic downturn. Thus, labor-cost-supporting programs aimed at these individuals, such as the creation of PUA under the CARES Act, can likewise be viewed as compatible with nonemployer survival capabilities. In contrast to microbusinesses, working capital loans may be only somewhat compatible with nonemployers' survival capabilities in the short term because revenues are not resilient. This contrasts with the medium term, where working capital loan programs can support nonemployers' reduced revenue models as the economy recovers, especially because these businesses have lower committed costs.

Finally, for enterprises, we find that these businesses exhibit slightly less revenue resiliency than microbusinesses, but their $50 \%$ greater labor flexibility, compared with microbusinesses, allows enterprises to decrease costs immediately for survival. However, enterprises also possess the greatest residual exposure to committed costs, which jeopardizes their short-term survival despite their greater labor flexibility. For businesses that reduce employee headcount as a means to survive a macro shock, labor cost grants and subsidies are not likely to be the most effective use of government support, consistent with Granja et al. (2020) and Chetty et al.'s (2020) findings regarding the low employment rate by firms (all enterprises) receiving a PPP loan. Likewise, similar to our assessment of nonemployers' survival capabilities, working capital loans may be less effective in supporting enterprises' survival capabilities in the short term because revenues are not as resilient, but they might support their reduced revenue models as the economy recovers. For enterprises, however, this support is overshadowed by the risk of failure caused by committed costs.

Short-term survival for enterprises requires support for their committed costs, such as those offered by commercial loans or debt-restructuring plans, enabling these businesses to manage larger fixed costs until they can restore revenues. Examples of these programs include state and local programs, such as Delaware County's Strong Small Business Support Program, which provides grants specifically for payments toward commercial lease obligations. More generally, these programs also include the newly enacted Small Business Reorganization Act of 2019 (SBRA). The SBRA created a new Subchapter V of Chapter 11 of the Bankruptcy Code, which greatly facilitates the use of a Chapter 11 reorganization for small businesses. Under Subchapter V, a small-business debtor can confirm a plan of reorganization without the consent of its long-term creditors while allowing the debtor to maintain its ownership interest. As such, it provides small businesses that are struggling under the weight of their long-term commitments with valuable leverage to renegotiate a commercial lease and other committed costs. Our findings indicate that these costs are most problematic for the survival of enterprises, making these programs especially relevant for these firms. 


\section{Testing Policies for Survival}

On June 3, 2020, the City of Oakland launched a follow-up survey, the Re-Opening and Recovery Survey, that asked approximately 300 businesses about the aid (if any) that they had pursued and received, as well as their short- and medium-term projections for survival. This survey provides a novel evaluation of the impact of policy programs and an opportunity to test the heterogeneous survival challenges faced by different-sized firms. In assessing this survey, we are cognizant of selection into applying to participate in a policy program as well as in survey participation. We address the issue of selection and discuss any limitations to the interpretation of our findings accordingly.

\section{A. Data and Statistics}

Our primary interest is in 2 dependent variables relating to the risk of shortterm closing and the ability to survive in the medium to long term. Both of these variables build off the following survey question: "If business disruption continues at the current rate, how soon will you be at risk of permanently closing your business?" The choices for answering this question are presented in Table 8, where we present summary statistics for the follow-up survey. We construct the SHORT_TERM_CLOSING variable as an indicator equal to 1 if a respondent either answered this question using the selection " 0 to 1 month" or indicated that the business was already closed in an open-ended question of actions taken, and 0 otherwise. We construct the variable MEDIUM_RUN_SURVIVING as an indicator equal to 1 if a respondent answered the aforementioned question by indicating that the business could sustain the present conditions for more than 6 months, and 0 otherwise. Overall, short-term closing represented $10 \%$ of the sample, whereas medium-run surviving businesses represented 35\%. This implies that without policy programs or improvements in the economy, the majority of respondents faced medium-run closure.

Our primary independent variables of interest are whether the business successfully applied for a PPP loan and whether the business owner successfully applied for PUA. Under the terms of the PPP, all respondents should have been eligible to apply for a PPP loan, given that the program was open to employer and nonemployer businesses having fewer than 500 employees, and all respondents reported having employee headcounts that would meet this requirement. ${ }^{10}$ Eligibility for PUA was limited to individuals who were not eligible for traditional unemployment insurance; therefore, it was available to respondents who were either nonemployer business owners or employer business owners who had laid off all employees and were seeking unemployment insurance for themselves personally. A large $59 \%$ of the survey respondents successfully applied for PPP loans,

\footnotetext{
${ }^{10}$ In addition to this size-based requirement, the PPP was also unavailable to businesses operating in select industries (e.g., a business primarily engaged in political or lobbying activities, businesses that derive more than a third of their revenue from gambling, etc.) and to applicants whose owners are disqualified because they are presently involved in a bankruptcy proceeding or have been convicted of committing certain felony offenses. Based on a review of the business names in this sample, we assume that none of the respondent businesses were ineligible for these reasons.
} 
TABLE 8

City of Oakland Re-Opening and Recovery Survey: Summary Statistics

Table 8 presents tabulations of the 278 responses from the June 2020 City of Oakland Re-Opening and Recovery Survey.

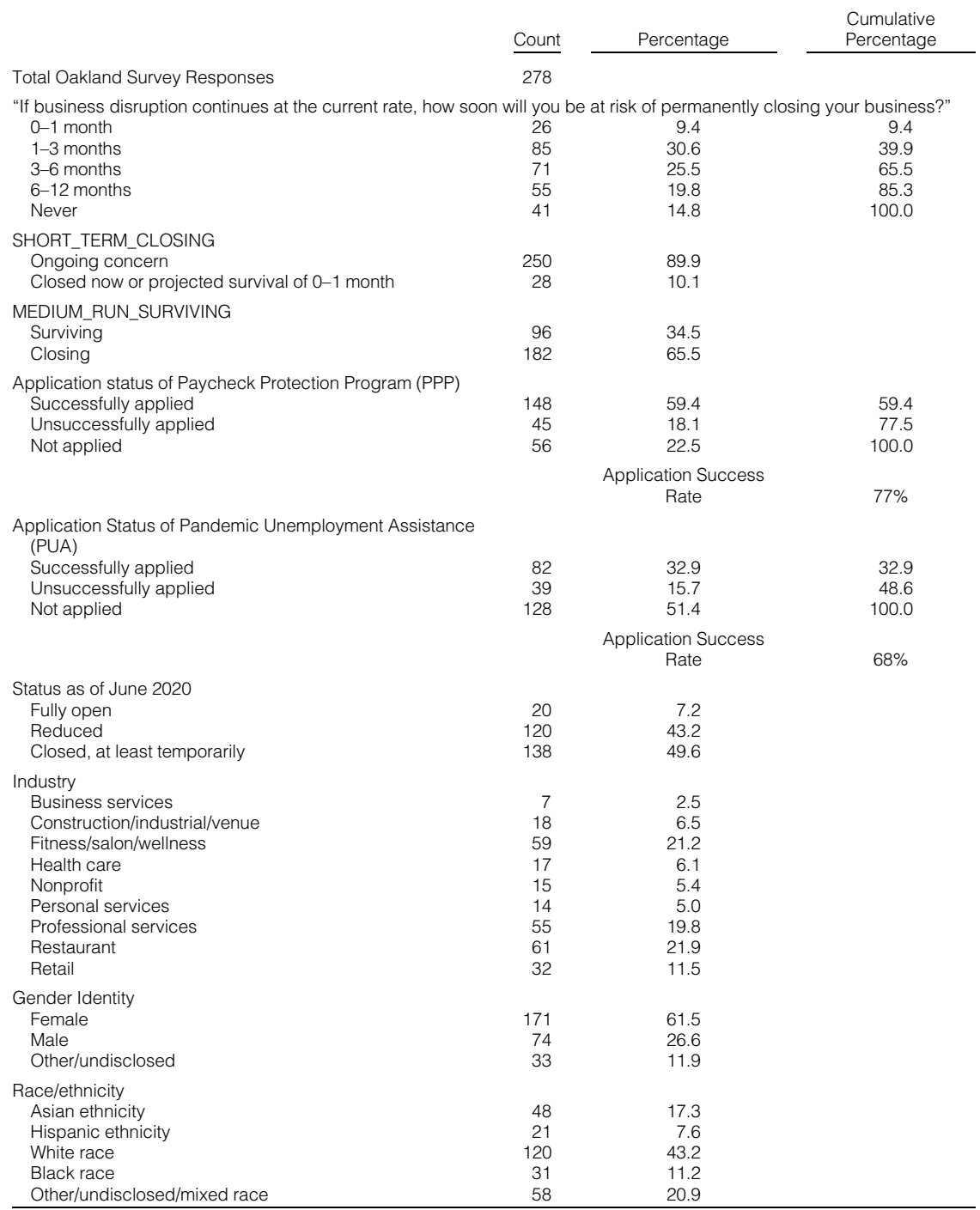

with an application success rate of $77 \%$. In addition, $32.9 \%$ of survey respondents successfully applied for PUA funds, with an application success rate of $68 \%$. Qualifying for PUA implies furloughing or laying off all employees, a seemingly optimal strategy for many survey respondents.

Finally, we have statistics regarding current operating status, industry, and owner demographics. The sample of firms represents a cross-section of industries, and half are coded as temporarily closed at the time of the survey. Sixty-two percent 
of the businesses are female-owned. The racial-ethnic breakdown of the sample is as follows: White (43\%), other/undisclosed/mixed race $(20.9 \%)$, Asian $(17.3 \%)$, Black (11.2\%), and Hispanic (7.6\%). Given our small sample, we do not try to do analysis within these categories.

\section{B. Methodology and Selection in Applying for PPP Loans and PUA}

A central concern in estimating any effect of a policy program on survival is selection with regard to survey completion and, especially, with regard to participating in the PPP or PUA programs. Small businesses may be experiencing differences in setting, in particular, differences in financial or economic distress, that would lead to filling out the survey or participating in the PPP or PUA programs.

The concern about selecting into the survey raises the question of generalizability but should not materially affect the analysis within that selection. The concern about selection in the applying for PPP or PUA assistance is fundamental to inference, however.

Our identification takes advantage of i) the existence of an "applied for" variable in the survey (APPLIED_PPP/APPLIED_PUA) that is specific to each program (with answer choices of "no," "yes, successfully," or "yes, unsuccessfully") combined with ii) the unique setting that neither policy required applicants to demonstrate financial need or lack of access to other finance. Finally, we also have iii) interim outcome variables of the status and actions taken by businesses to provide selection tests and conditioning variables.

Our identification relies on the idea that application success rates were likely to vary across applicants in ways that were largely orthogonal to unobservable factors affecting medium-term survival. The viability of this assertion is stronger for the PPP than the PUA. Early reports indicate that PPP applicants were often unable to acquire a PPP loan because of technological problems incurred by the applicant's bank or because its lender was otherwise unable to process the loan as a result of confusion over the application of bank-secrecy protocols to PPP loans. ${ }^{11}$ This variation accordingly allows us to estimate the effect of the PPP à la the idea of the instrument used in Granja et al. (2020). Said more directly, in our sample, of the Oakland businesses applying for a PPP loan, a quarter were unsuccessful in their application attempt. The lack of success of these businesses is likely to be largely noise, given the power in the first stage of Granja et al. (2020). In this regard, it is also worth reiterating that the survey did not ask business owners who applied for the PPP or PUA if they accepted or rejected funding once approved but, rather, if the owner successfully or unsuccessfully applied. Overall, we believe that this approach to identification makes it plausible to isolate a causal effect of the PPP on business medium-run outcomes. That said, in the discussion that follows, we refrain

\footnotetext{
${ }^{11}$ For instance, lack of guidance from the SBA caused banks to vary in the stringency with which they applied the Bank Secrecy Act to loan applicants, which could result in a PPP denial. See Jensen, "Payroll Protection Program and the Bank Secrecy Act: Balancing Aid to Small Businesses with Financial Crime Risks," White \& Case Memo, Apr. 17, 2020. Banks also experienced difficulties in processing PPP loan applications as a result of problems in accessing the SBA's overwhelmed E-Tran portal. See "Banks Report E-Tran Difficulties; SBA Lowers PPP Bulk Submission Threshold," ABA Banking Journal, Apr. 27, 2020.
} 
from using this language because our sample is small, and we cannot prove the randomness of the PPP application success or unsuccess of the Oakland businesses.

Our first use of the APPLIED_PPP/APPLIED_PUA variable is through a simple selection test that examines whether businesses that were successful in applying for a PPP loan or PUA differed in setting. We use the APPLIED_PPP/APPLIED_PUA variable in combination with information on the businesses' current operating status and an action-taken variable to test for residual selection in successfully applying for a PPP or PUA beyond the decision to apply. The OPERATING STATUS variable is the answer to the question of whether the business (in June 2020) is open, reduced, or closed in its business operations. The ACTION TAKEN variables provide information on whether and how a business has adjusted to the crisis, with answers as follows: "furloughing employees" (20.1\%), "having employees work remotely" (18.0\%), "no action" (13.3\%), "reduced employees' hours" $(10.4 \%)$, and "laid off employees" (7.9\%). We note that some of the differences in these OPERATING_STATUS and ACTION_TAKEN variables may be an outcome of the PPP because early June is after the PPP's first wave and some of the second wave. Yet we prefer to err on overcontrolling for this possibility rather than overinterpreting our medium-run survival results.

Table 9 presents selection tests. The dependent variable in columns $1-2$ is an ordered logit specification of OPERATING_STATUS: closed $<$ reduced $<$ open. The dependent variables in columns 3-10 are the ACTION_TAKEN options listed previously, cast as indicator variables for each answer. In the odd columns of the table, we include only indicators for whether a business successfully applied for the PPP or PUA (SUCCESS_PPP/SUCCESS_PUA), plus industry fixed effects. In the even columns, we include variables for applying for each program, allowing us to gauge the selection of applying versus application success. At the bottom of the table, we do the addition of the two coefficients (because success is the union of applying for the program and succeeding) and show the significance test.

We find that successfully applying for the PUA is highly endogenous to intermediate status. This is not terribly surprising because the businesses with employees generally must eliminate all employees in order to qualify as a nonemployer. We see this result in the ordered logit of OPERATING_STATUS, as well as on the indicator for the ACTION_TAKEN of "having employees work remotely."

However, the PPP results are quite different. Focusing on the even-numbered columns, we find that although OPERATING_STATUS and ACTION_TAKEN are associated with success in a PPP application in some columns, these effects are generally offsetting to the coefficient for applying for a PPP loan. Granted, such an offsetting pattern is associated with collinearity concerns, but we also show the same pattern without the APPLIED_PPP variable. The only interim variable that suggests a concern is the "furloughing employees" variable. In the survival analysis that follows, we therefore present results with and without businesses that express this interim action.

\section{PPP and PUA Results}

Table 10 presents estimates for our policy tests. Columns 1-3 examine the association between policy program application success and short-term permanent closure; columns 4-7 examine the association between application success and 
TABLE 9

\section{Selection Tests on Intermediate Outcomes and Actions}

The sample in Table 9 is the data set of 278 survey responses from the City of Oakland Re-Opening and Recovery Survey. The observation-count differences across columns come from fully determined observations in the estimation, not missing information. Columns 1 and 2 report an ordered logit estimation of the OPERATING_STATUS of the firm in June 2020 (closed < reduced operations < open fully). Coefficients are in log odds ratios of moving from any level of openness to the next. Columns 3-10 present logit estimations of the indicator variables listed in the columns, which are answers to the ACTION_TAKEN question, with marginal effects shown. Industry effects are included and not shown. The displayed independent variables for each of the Paycheck Protection Program (PPP) and Pandemic Unemployment Assistance (PUA) policies are whether the owner applies for the policy, and if so, whether the application is successful. Because the full marginal effect of success is applying and succeeding, the sum of the marginal effects and its standard error are reported in the lower rows. Robust standard errors are in parentheses. ${ }^{*},{ }^{* *}$, and ${ }^{* * *}$ indicate statistical significance at the $10 \%, 5 \%$, and $1 \%$ levels, respectively.

Model Ordered Logit

Business Status

Dependent Variable

OPERATING_STATUS (Closed < Reduced < Open)

APPLIED_PPP

SUCCESS_PPP

1

APPLIED_PUA

SUCCESS_PUA

$-1.316^{\star \star \star}$
$(0.324)$

Estimate: APPLIED_PPP + SUCCESS_PPP

Estimate: APPLIED_PUA + SUCCESS_PUA

Odds ratio

Industry fixed effects

No. of obs.

Pseudo- $R^{2}$

Yes
278

278
0.170

\begin{tabular}{c}
2 \\
\hline-0.738 \\
$(0.460)$ \\
$0.791^{\star}$ \\
$(0.413)$ \\
$-0.749^{\star \star}$ \\
$(0.368)$ \\
-0.670 \\
$(0.427)$ \\
0.053 \\
$(0.333)$ \\
$-1.419^{\star \star \star}$ \\
$(0.338)$ \\
0.244 \\
Yes \\
278 \\
0.186
\end{tabular}

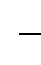

Furloughed Employees $\quad$ ACTION_TAKEN

Furloughed Employees

3

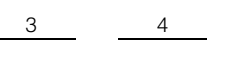

$0.104^{\star \star}$

(0.0494)

$\overline{-0.0043}$

$(0.0831)$

0.0681
$(0.0705)$

$-0.0398$

$(0.0544)$

-0.0938
$(0.0770)$

$0.107^{\star}$

$0.107^{*}$

$(0.055)$
-0.026

(0.056)

$\begin{array}{ccc}5 & & 6 \\ & & -0.206^{\star \star} \\ 0.0605 & & 0.102) \\ (0.0519) & & \left(0.208^{\star \star}\right. \\ & & -0.0424 \\ & & (0.0697) \\ -0.218^{\star \star *} & & -0.176^{\star} \\ (0.0705) & & (0.0932) \\ & & 0.002 \\ & & (0.070) \\ & -0.218^{\star \star \star} \\ & (0.054)\end{array}$

Laid Off Employees 7

\subsection{8}$$
\text { (0.0439) }
$$$$
-0.0362
$$$$
\begin{gathered}
-0.0362 \\
(0.0560)
\end{gathered}
$$

$0.0560)$

\begin{tabular}{c}
8 \\
\hline 0.0359 \\
$(0.0736)$ \\
-0.00721 \\
$(0.0655)$ \\
-0.0441 \\
$(0.0764)$ \\
-0.00391 \\
$(0.0814)$ \\
0.029 \\
$(0.057)$ \\
-0.048 \\
$(0.050)$
\end{tabular}

Reduced Employee Hours

9

-0.114
$(0.106)$

0.0526

$(0.0540)$

0.131

(0.0990)

$-0.0615$

(0.0931)

$0.042 \quad 0.110$

$(0.0540) \quad(0.102)$

0.016

(0.058)

0.049

$(0.057)$

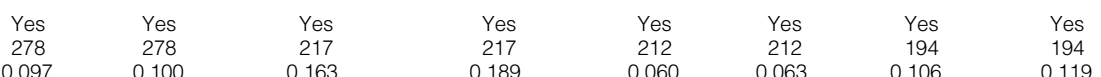

$278-278$

0.163

0.189

0.060

0.063

0.119 
TABLE 10

Did the PPP and PUA Programs Save Businesses?

The sample is small businesses in the City of Oakland Re-Opening and Recovery Survey. All estimations are via logit specifications, presenting marginal effects. Both dependent variables build off the following survey question: "If business disruption continues at the current rate, how soon will you be at risk of permanently closing your business?" The dependent variable in columns 1 and 2, SHORT_TERM_CLOSING, is an indicator equal to 1 if the answer to this question is $0-1$ month or if the respondent indicates elsewhere that the business is permanently closed already, and 0 otherwise. The dependent variable in columns 3 and 4 MEDIUM RUN SURVIVING is equal to 1 if the (the owner) in the precrisis period; whether the owner (the ow errors are in parentheses. ${ }^{*}{ }^{* *}$, and ${ }^{* * *}$ indicate statistical significance at the $10 \%, 5 \%$, and $1 \%$ levels, respectively.

Dependent Variable

Model

APPLIED_PPP

SUCCESS_PPP

SUCCESS_PPP $\times$ LOG_WORKERS (precrisis)

APPLIED_PUA

SUCCESS_PUA

SUCCESS_PUA $\times$ LOG_WORKERS (precrisis)

LOG_WORKERS (precrisis)

NONEMPLOYER

Fixed effects included:

Industry

Gender identity

Race/ethnicity

Status

Action steps

Drops furloughing firms

No. of obs.

Pseudo- $R$

\begin{tabular}{ccc}
\multicolumn{2}{c}{ Logit Marginal Effects } \\
\cline { 1 - 1 } 1 & & 2 \\
& & 0.0163 \\
& & $(0.0582)$ \\
0.0573 & & 0.0606 \\
$(0.0717)$ & & $(0.0825)$ \\
-0.0206 & & -0.0232 \\
$(0.0431)$ & & $(0.0435)$ \\
& & 0.0641 \\
& & $(0.0571)$ \\
$-0.168^{\star \star}$ & & $-0.205^{\star \star}$ \\
$(0.0756)$ & & $(0.0827)$ \\
$0.164^{\star \star \star}$ & & $0.159^{\star \star \star}$ \\
$(0.0445)$ & & $(0.0436)$ \\
-0.0162 & & -0.0135 \\
$(0.0444)$ & & $(0.0452)$ \\
-0.0473 & & -0.0501 \\
$(0.0731)$ & & $(0.0711)$
\end{tabular}

al Effects $\underline{\text { Linear Probability }}$

3

0.0161

0.053

(0.0797)

$-0.0166$

(0.0206)

0.0495

(0.0619)

$-0.142^{\star}$

(0.0819)

$0.129^{* *}$

$(0.0505)$

0.00343

$(0.0139)$

$-0.0369$

$(0.0626)$

\begin{tabular}{|c|c|c|c|c|c|c|}
\hline Yes & Yes & Yes & Yes & Yes & Yes & Yes \\
\hline Yes & Yes & Yes & Yes & Yes & Yes & Yes \\
\hline Yes & Yes & Yes & Yes & Yes & Yes & Yes \\
\hline- & - & - & - & - & - & Yes \\
\hline- & - & - & - & - & - & Yes \\
\hline- & - & - & - & - & Yes & - \\
\hline 238 & 238 & 278 & 278 & 278 & 222 & 278 \\
\hline 0.277 & 0.288 & 0.208 & 0.210 & 0.237 & 0.279 & 0.268 \\
\hline
\end{tabular}


medium-term survival. All columns include industry, gender identity, and race/ ethnicity fixed effects. We discuss each policy in turn.

We find that application success for the PPP has no association with SHORT_TERM_CLOSING, consistent with the results of Chetty et al. (2020) and Granja et al. (2020). Column 1 of Table 10 presents the results excluding the indicators for whether a business applied for either program, to be able to compare magnitudes when absorbing any selection in applying, which we add in column 2. Column 3 differs from column 2 in that we use a linear probability model to show that the selection of the perfectly determined variables in the logit (which drop from the estimation) is not influential (note the difference in observations). We find no result relating the PPP to short-term closure with or without the application variable.

However, the results are quite different with respect to MEDIUM_RUN_ SURVIVING. Success in a PPP application increases the medium-run survival probability by $27 \%$ in column 4 of Table 10 . In column 5 , the result holds when we add the application indicators to address selection. The result continues to hold when we drop furloughing firms (column 6) and when we add in controls for interim status and actions taken (column 7). The sum of the coefficients for APPLIED_PPP and SUCCESS_PPP in column 5 is 0.205 , suggesting that our efforts to address selection diminishes the effect of the PPP on increasing medium-run survival by $27 \%$ to $20.5 \%$.

The finding that PPP application success is strongly associated with increasing firm survival in the medium run by $20.5 \%$ is in stark contrast to the implications that the PPP was ineffective, as in the employment results in Chetty et al. (2020) and Granja et al. (2020). The difference is surely due to our being able to study mediumrun effects (and even control for short-term status) and to the fact that prior work has focused on larger small businesses. Consistent with our results, Granja et al. (2020) foreshadows our finding insofar that businesses taking PPP loans in their sample note that they are either making productive use of the capital or saving for survival purposes. We confirm their intuition.

Our second main result on the PPP effect concerns heterogeneous effects by firm size. Looking at the interaction of LOG_WORKERS (precrisis) and the SUCCESS_PPP indicator, we find that as businesses increase in precrisis employee count, the PPP is no longer associated with staving off closure. Again, we are cognizant that selection could differentially affect firms of different sizes, but we note that the selection story on the interaction is one of differential status by firm size, whose sign is likely to suggest our interaction results are conservative. ${ }^{12}$

The Oakland data thus reveal heterogeneous effects of the PPP on mediumterm closure risk by firm size. Using the estimates from column 5, we plot this

\footnotetext{
${ }^{12}$ This interaction finding gives direction to the rival selection story and affords us a partial test. In particular, for this interaction effect to be the product of selection, it must be the case that among PPP recipients, revenues for larger enterprises are sufficiently distressed that these enterprises are likely to close in the medium term. Conversely, revenues for microbusinesses that receive PPP loans must be sufficiently strong that they are likely to remain open. To examine whether this is the case, we test the association between OPERATING_STATUS (open > reduced > closed) and LOG_WORKERS (precrisis) and its interaction with whether a respondent successfully applied for a PPP loan, holding industry effects constant. The results (unreported) reveal a significant interaction between LOG_WORKERS and PPP success, indicating that (if anything) enterprises were experiencing stronger revenues than microbusinesses, the opposite of what would be required for selection to drive this result.
} 


\section{FIGURE 8}

\section{Effect of the PPP on Medium-Run Survival}

The sample in Figure 8 is small businesses in the City of Oakland Re-Opening and Recovery Survey. Plotted is the predicted effect of firm size on medium-run survival, measured as the response to the question asking, "If business disruption continues at the current rate, how soon will you be at risk of permanently closing your business?" from column 5 of Table 10, taking into account the coefficients on APPLIED_PPP, SUCCESS_PPP, and SUCCESS_PPP $\times$ LOG_WORKERS.

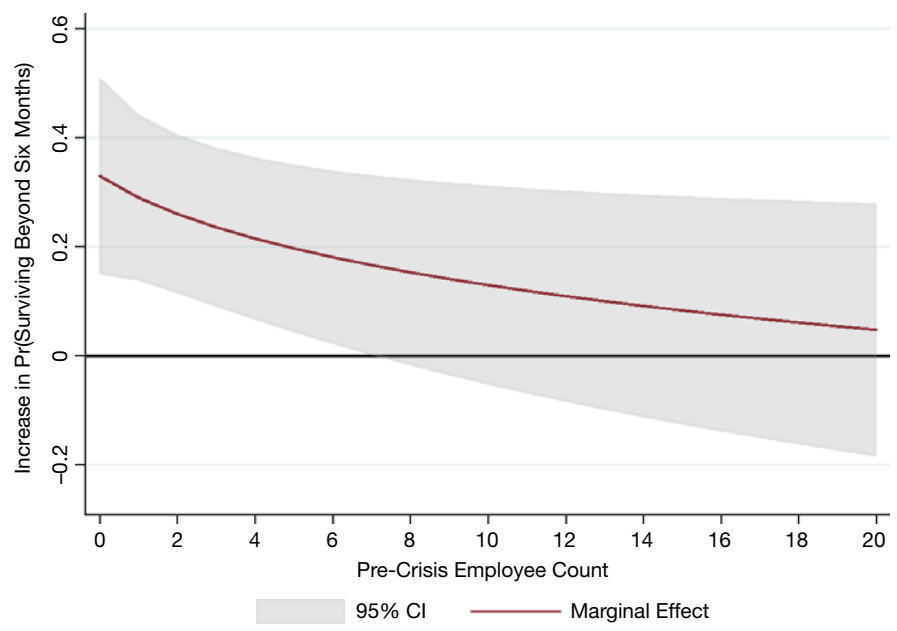

pattern in Figure 8, noting that the effect becomes economically immaterial after approximately 20 employees. Note that in the 2015 census data, $92.9 \%$ of businesses and $17 \%$ of employment are in businesses with under 20 employees.

In addition to this result being consistent with Granja et al. (2020) (who find no overall effect on closure rates among larger small businesses receiving PPP loans), this result is a test of our compatibility findings. We suggested earlier in this section that labor-cost-supporting programs would be less effective for enterprises because these organizations use labor flexibility as their survival strategy. To be sure, a larger business could use up to $40 \%$ of the PPP loan toward nonpayroll costs if it desired loan forgiveness or even more than this amount if it chose to use the PPP loan for nonpayroll costs and then repay the loan in 2 years. ${ }^{13}$ Our data do not permit us to examine the extent to which larger firms deployed their PPP funds; therefore, we cannot distinguish whether the reason for its ineffectiveness on medium-term survival for larger firms was due to the fact that the amount was insufficient (e.g., because the borrower used only $40 \%$ toward nonpayroll costs or because PPP loan amounts were based solely on past payroll expenses) or simply because the program was cast as a payroll subsidy. That it was most effective for microbusinesses and not enterprises is nevertheless consistent with our compatibility findings.

Turning to the PUA results, we find an opposite pattern. PUA success is negatively associated with short-term closure but has no association with mediumterm survival. In the short term, business owners who were successful in their PUA application shuttered their operations with a 9.4\%-19.1\% lower probability,

\footnotetext{
${ }^{13}$ In the event a PPP borrower failed to qualify for loan forgiveness, PPP loans issued during the sample period would have a $1 \%$ interest rate and a 2 -year maturity.
} 
suggesting that owners were relying on the PUA to replace their lost business income to remain in operation. However, this result does not hold for the larger enterprises; we see that the coefficient on LOG_WORKERS (precrisis) interacted with the PUA indicator is positive. This latter result should be expected: Recall that for larger firms, taking PUA implies that the business had to first lay off all workers. Thus, this unwinding of the effectiveness of the PUA for these businesses is a mingling of the selection of already-struggling businesses to apply for PUA with the inability of the PUA's income substitution (roughly $\$ 600$ per week) to support the owner of a business that has lost so much revenue that it has presumably let go of all of its employees.

\section{Conclusion}

The bundling of small businesses into one category is too coarse for designing small-business assistance programs during periods of macro distress. Using a unique set of data, we show that in Oakland, small businesses, all facing distress during the COVID-19 pandemic, have notably different survival capabilities concerning strategies focused on revenue resilience, labor flexibility, and committed costs. Moreover, these survival capabilities differ systematically by the size of a firm.

Our punchline, however, is not simply that these differences exist but also that they have significant policy relevance with regard to the design of small-business assistance programs. The PPP provides an especially costly example of this basic point. Originally designed as a $\$ 610$-billion program to assist U.S. small businesses, the PPP loan-forgiveness requirements effectively made the program a labor subsidy. Our unique survey data permit us to show that such a subsidy was especially effective for the medium-term survival of microbusinesses, but we also show that the labor-focused strategy of the PPP runs counter to the survival capabilities of larger enterprises that focus on scaling back labor costs. ${ }^{14}$

Our framework also provides an important tool for researchers in evaluating the effectiveness of small-business assistance programs. Again, the PPP and early studies of its effect on small-business payrolls provide an example. As noted, Chetty et al. (2020) find that the PPP had no meaningful impact on employment rates, leading these authors to conclude that liquidity is insufficient to restore employment at small businesses. By focusing on enterprises having an average of 45 employees or more, however, the study's data would not have been able to identify heterogeneous treatment effects for the PPP within the universe of small businesses. As we show, expressly grappling with the different survival capabilities of microbusinesses highlights how labor subsidies are likely to be especially helpful to these firms while being less helpful to the enterprises studied by Chetty et al.

Finally, our findings speak to the broader policy question of how to optimally support small businesses through a crisis, given existing evidence that differentsized small businesses have differential welfare effects. In particular, researchers examining growth patterns among small businesses have highlighted considerable

\footnotetext{
${ }^{14}$ In this regard, our article complements several recent articles that show the effectiveness of the PPP on firm survival when the sample of small businesses includes smaller establishments (see, e.g., Hubbard and Strain (2020), Faulkender, Jackman, and Miran (2021)).
} 
heterogeneity regarding the growth prospects of small businesses, particularly between employer and nonemployer businesses (Decker et al. (2014), Hurst and Pugsley (2011)). Differences likewise exist in the extent to which small businesses contribute to community vibrancy. In combination, these findings provide good reason for policy makers concerned with promoting job growth to focus on assisting those small businesses we classify as enterprises, whereas those concerned with community vibrancy and local tax bases would be well advised to focus on assisting nonemployers and microbusinesses.

Although it is beyond the scope of this article to address how to prioritize these competing considerations, we view our findings as providing two pieces of information that are critical to its resolution. The first concerns the importance of mapping specific programs to the desired beneficiaries of small-business support programs. As we show, differentials in survival capabilities across firms have implications for how to best support firms of different sizes; that is, although labor subsidies may be effective for supporting microbusinesses, facilitating lease forgiveness may be more effective for larger enterprises.

The second relates to the temptation to focus exclusively on job growth in the design of small-business survival, particularly given the fiscal costs these programs can entail. Within our data, we find that the survival capabilities of nonemployers and microbusinesses provide welfare effects that would be imprudent to dismiss. It is the microbusinesses that are the most revenue resilient, despite their need to cover a less flexible labor-cost structure. During the COVID-19 crisis, these businesses pulled their weight in supporting the local economy insofar that they displayed revenue resilience. This revenue resilience translates to income to support the local economy through preserved returns to labor and sales receipts, as well as to their property bases. Similarly, nonemployer proprietors, either because of their greater economic flexibility or the potential to realize nonmonetary utility from operations, may be more likely to choose to continue operations regardless of the level of demand for their services. These businesses may not support the labor force or sales/ business taxes with their low-return businesses, but to the extent that they are central to establishment proliferations (Hurst and Pugsley (2011)) and to the extent that establishments lead to community vibrancy, these businesses' self-effort and sometimes self-funded resiliency are valuable to the community.

In short, the framework we provide should enable policy makers to design small-business support programs that are both better informed and more effective in achieving the welfare objectives that justify their creation.

\section{References}

Adams, A.; T. Boneva; M. Golin; and C. Rauh. "Inequality in the Impact of the Coronavirus Shock: Evidence from Real Time Surveys.” Technical Report, Mimeo (2020).

Alekseev, G.; S. Amer; M. Gopal; T. Kuchler; J. W. Schneider; J. Stroebel; and N. C. Wernerfelt. "The Effect of COVID-19 on U.S. Small Businesses: Evidence from Owners, Managers, and Employees." NBER Working Paper No. 27833 (2020).

Alm, J.; R. D. Buschman; and D. L. Sjoquist. "Foreclosures and Local Government Revenues from the Property Tax: The Case of Georgia School Districts." Regional Science and Urban Economics, 46 (2014), 1-11.

Alstadsæter, A.; J. B. Bjørkheim; W. Kopczuk; and A. Økland. "Norwegian and US Policies Alleviate Business Vulnerability Due to the COVID-19 Shock Equally Well.” NBER Working Paper No. 27637 (2020). 
Austin, B.; E. Glaeser; and L. Summers. "Saving the Heartland: Place-Based Policies in 21st Century America." Brookings Papers on Economic Activity (2018), 151-255.

Bartik, A. W.; M. Bertrand; Z. Cullen; E. L. Glaeser; M. Luca; and C. Stanton. "How Are Small Businesses Adjusting to COVID-19? Early Evidence from a Survey." NBER Working Paper No. 26989 (2020).

Bartik, A. W.; M. Bertrand; F. Lin; J. Rothstein; and M. Unrath. "Measuring the Labor Market at the Onset of the COVID-19 Crisis: Evidence from Traditional and Non-Traditional Data" Brookings Papers on Economic Activity, Special Edition: COVID-19 and the Economy (2020), 239-326.

Bartik, A. W.; Z. Cullen; E. L. Glaeser; M. Luca; C. Stanton; and A. Sunderam. "The Targeting and Impact of Paycheck Protection Program Loans to Small Businesses." NBER Working Paper No. 27623 (2020).

Bhutta, N.; J. Blair; L. Dettling; and K. Moo. "COVID-19, the CARES Act, and Families' Financial Security.” National Tax Journal, 73 (2020), 645-672.

Chetty, R.; J. Friedman; N. Hendren; M. Stepner; and the Opportunity Insights Team. "How Did COVID-19 and Stabilization Policies Affect Spending and Employment? A New Real-Time Economic Tracker Based on Private Sector Data.” NBER Working Paper No. 27431 (2020).

Davis, S. J.; J. Haltiwanger; R. S. Jarmin; C. J. Krizan; J. Miranda; A. Nucci; and K. Sandusky. "Measuring the Dynamics of Young and Small Businesses: Integrating the Employer and Nonemployer Universes.” In Producer Dynamics, T. Dunne, J. B. Jensen, and M. J. Roberts, eds. Chicago, IL: University of Chicago Press (2009).

Davis, S. J.; J. Haltiwanger; and S. Schuh. Job Creation and Destruction. Cambridge, MA: MIT Press (1996).

Decker, R.; J. Haltiwanger; R. S. Jarmin; and J. Miranda. "The Role of Entrepreneurship in US Job Creation and Economic Dynamism.” Journal of Economic Perspectives, 28 (2014), 3-24.

Erel, I., and J. Liebersohn. "Does FinTech Substitute for Banks? Evidence from the Paycheck Protection Program.” NBER Working Paper No. 27659 (2020).

Fairlie, R. "The Impact of COVID-19 on Small Business Owners: Evidence from the First 3 Months After Widespread Social-Distancing Restrictions." Journal of Economics and Management Strategy, 29 (2020), 727-740.

Faulkender, M.; R. Jackman; and S. I. Miran. "The Job-Preservation Effects of Paycheck Protection Program Loans.” Office of Economic Policy Working Paper 2020-01 (2021).

Freedman, R. "75\% Payroll Rule Makes PPP Loans Useless, Business Owners Say,” available at https:// www.cfodive.com/news/payroll-rule-paycheck-protection-program-useless-coronavirus/577213/ (2020).

Granja, J.; C. Makridis; C. Yannelis; and E. Zwick. "Did the Paycheck Protection Program Hit the Target?" NBER Working Paper No. 27095 (2020).

Haltiwanger, J.; R. S. Jarmin; and J. Miranda. "Who Creates Jobs? Small vs. Large vs. Young.” Review of Economics and Statistics, 95 (2013), 347-361.

Hubbard, G., and M. R. Strain. "Has the Paycheck Protection Program Succeeded?" Conference Draft, Brookings Papers on Economic Activity (2020).

Humphries, J. E.; C. Neilson; and G. Ulyssea. "The Evolving Impacts of COVID-19 on Small Businesses Since the Cares Act." Cowles Foundation Discussion Paper No. 2230 (2020).

Hurst, E., and B. W. Pugsley. "What Do Small Businesses Do?” Brookings Papers on Economic Activity (2011), 73-118.

Iverson, B.; R. Kluender; J. Wang; and J. Yang. "Bankruptcy and the COVID-19 Crisis.” Working Paper, available at https://papers.ssrn.com/sol3/papers.cfm?abstract id=3690398 (2020).

Kim, O.; J. A. Parker; and A. Schoar. "Revenue Collapses and the Consumption of Small Business Owners in the Early Stages of the COVID-19 Pandemic." NBER Working Paper No. 28151 (2020).

Mayer, C.; D. S. Siegel; and M. Wright. "Entrepreneurship: An Assessment." Oxford Review of Economic Policy, 34 (2018), 517-539.

Moskowitz, T. J., and A. Vissing-Jørgensen. "The Returns to Entrepreneurial Investment: A Private Equity Premium Puzzle?” American Economic Review, 92 (2002), 745-778.

Rajan, R. "Businesses Cannot Simply Awake from This Coma and Carry On.” Financial Times, May 12 (2020).

Shoag, D., and S. Veuger. "Shops and the City: Evidence on Local Externalities and Local Government Policy from Big-Box Bankruptcies." Review of Economics and Statistics, 100 (2018), 440-453.

Tsivanidis, N., and M. Gechter. "Spatial Spillovers from Urban Renewal: Evidence from the Mumbai Mills Redevelopment.” Working Paper, Pennsylvania State University (2020).

U.S. Census. "Small Business Pulse Survey: Tracking Changes during the Coronavirus Pandemic." Available at https://portal.census.gov/pulse/data/\#downloads (2020).

U.S. Small Business Administration. “A Look at Nonemployer Businesses.” Available at https:// www.sba.gov/sites/default/files/advocacy/Nonemployer-Fact-Sheet.pdf (2018).

U.S. Small Business Administration. “Applying for Economic Injury Disaster Loans.” Available at https:// www.sba.gov/sites/default/files/resource_files/EIDL-BDO_Presentation_March_26_0.pdf (2020). 